\title{
Are There Too Many Safe Securities? Securitization and the Incentives for Information Production
}

\section{Citation}

Hanson, Samuel Gregory, and Aditya Vikram Sunderam. "Are There Too Many Safe Securities? Securitization and the Incentives for Information Production." Journal of Financial Economics (forthcoming). (Internet Appendix: http://www. people.hbs.edu/shanson/ info_tranching_appendix_20120907.pdf)

\section{Permanent link}

http://nrs.harvard.edu/urn-3:HUL.InstRepos:10578869

\section{Terms of Use}

This article was downloaded from Harvard University's DASH repository, and is made available under the terms and conditions applicable to Open Access Policy Articles, as set forth at http:// nrs.harvard.edu/urn-3:HUL.InstRepos:dash.current.terms-of-use\#OAP

\section{Share Your Story}

The Harvard community has made this article openly available. Please share how this access benefits you. Submit a story.

Accessibility 


\title{
Are there too many safe securities? Securitization and the incentives for information production*
}

\author{
Samuel G. Hanson \\ Harvard Business School \\ shanson@hbs.edu
}

\author{
Adi Sunderam \\ Harvard Business School \\ asunderam@hbs.edu
}

September 2012

\begin{abstract}
We present a model that helps explain several past collapses of securitization markets. Originators issue too many informationally insensitive securities in good times, blunting investor incentives to become informed. The resulting endogenous scarcity of informed investors exacerbates primary market collapses in bad times. Inefficiency arises because informed investors are a public good from the perspective of originators. All originators benefit from the presence of additional informed investors in bad times, but each originator minimizes his reliance on costly informed capital in good times by issuing safe securities. Our model suggests regulations that limit the issuance of safe securities in good times.
\end{abstract}

\footnotetext{
${ }^{*}$ We are grateful to David Scharfstein and Jeremy Stein for their guidance throughout this project. We thank David Berger, Eric Budish, John Campbell, Sergey Chernenko, Josh Coval, Emmanuel Farhi, Robin Greenwood, Denis Gromb, Bengt Holmstrom, Judd Kessler, Josh Schwartzstein, Andrei Shleifer, Alp Simsek, Erik Stafford, Luis Viceira, and seminar participants at the 2012 AFAs, Boston University SOM, Cornell Johnson, Dartmouth Tuck, the Deutsche Bank/Chicago Booth Symposium, the Federal Reserve Bank of New York, Harvard Business School, LBS, LSE, MIT Sloan, NYU Stern, Ohio State Fisher, Washington University Olin, Wharton, and Yale SOM for helpful comments and suggestions. We also thank Mary Goodman, Matt Kabaker, Andrew Metrick, Morgan Ricks, David Scharfstein, Jeremy Stein, and Larry Summers for early conversations that helped shape the ideas in this paper.
} 


\section{Introduction}

Many accounts of the rise of securitization argue that tranching - manufacturing claims with different degrees of seniority - helps economize on information production costs. ${ }^{1}$ Without tranching, many investors would have incentives to produce information about asset cash flows. While information production helps allocate capital efficiently, duplicating it across many investors may be inefficient.

Tranching cash flows into senior and junior securities helps minimize such duplication. Informationally insensitive senior securities (i.e., AAA-rated senior tranches) are nearly riskless, so investors can hold them without expending significant resources on information acquisition. Information production can then be carried out by a handful of specialized investors who hold informationally sensitive junior securities (equity tranches), and duplication is minimized.

However, as noted by Gorton (2008a,b), economizing on information production costs in good times may set the stage for market collapses in bad times, when the scope for adverse selection rises dramatically. Indeed, while the recent financial crisis provides the most prominent example, primary markets for near-riskless securities have suffered numerous shutdowns in the last 40 years as we discuss below. This suggests that instability could be a general characteristic of markets for near-riskless securities, not just a one-time problem associated with the recent subprime mortgage crisis. The critical question is whether these shutdowns are inefficient. Since bad states are rare, the benefits of economizing on information production in good times could outweigh the costs of collapse in bad times.

We present a model in which inefficient collapses arise from the interaction between issuer security design decisions and investor information acquisition decisions. Securitization blunts investor incentives to build the "information production infrastructure" needed to analyze securitization cash flows. For an investment fund to produce information about a securitization, it must have databases of historical loan performance, Monte Carlo models to simulate asset cash flows, and highly trained analysts. This infrastructure is costly to build and has limited value when most securities are informationally insensitive. Securitization helps economize on infrastructure costs by allowing issuers to create informationally insensitive securities that do not require analysis. However, privately optimal securitization can produce an excessive amount of informationally insensitive securities in good times, endogenously resulting in inefficiently low levels of information infrastructure, which exacerbates collapses in bad times.

In our model, originators wish to finance positive NPV loan pools using securitization. Specifically, each originator raises financing by issuing a combination of debt and equity backed by his loan pool in the primary market. Prior to this financing decision, investors may make an irreversible decision to build information production infrastructure. The number of investors who choose to build infrastructure is the key endogenous variable in the model. Investors who

\footnotetext{
${ }^{1}$ See, for example, Gorton and Pennacchi (1990), Duffie and DeMarzo (1999), DeMarzo (2005), Gorton (2008a,b), Dang, Gorton, and Holmstrom (2010).
} 
choose not to build infrastructure (the "uninformed") may face adverse selection when they trade with investors who do build infrastructure (the "informed") in the secondary market. However, unlike the uninformed, the informed must in equilibrium earn sufficient profits to recoup their up-front costs of building infrastructure.

Through the informational sensitivity of the securities they issue, originators control the profits that informed investors earn. In good times, differences in loan pool payoffs are relatively small, so the scope for adverse selection is low. Thus, originators can primarily finance their loan pools by issuing informationally insensitive debt, which leaves informed investors with little ability to earn profits. This in turn discourages investors from building information infrastructure ex ante.

In bad times, however, the payoffs on bad pools fall and the scope for adverse selection increases. This significantly reduces the amount of funding originators can raise from uninformed investors. Informed investors, by contrast, are relatively immune to adverse selection problems. They are a robust source of capital in bad times, but there are relatively few of them. Thus, even though the average loan pool is still positive NPV, loan origination collapses because it becomes constrained by the limited amount of informed capital already in place.

In contrast to much of the previous work on security design and adverse selection, the private market outcome can be inefficient in our model because of a financing friction: the full surplus associated with loan pools cannot be pledged to informed investors. This friction, which can be motivated by moral hazard considerations, means that the private returns to becoming informed may be lower than the social returns. This implies that the number of investors who endogenously choose to become informed can be inefficiently low in the private market equilibrium. The key point of our paper is that even though informed investors create adverse selection problems, it may be optimal to encourage, rather than discourage, their entry because they are a robust source of capital in bad times.

A social planner can overcome the financing friction and increase total surplus by regulating originator capital structure decisions to increase the issuance of risky, informationally sensitive securities from which informed investors can profit in good times. Intuitively, such regulations are "in-kind" subsidies to informed investors: originators sacrifice a small portion of their profits in good times to encourage more investors to become informed. The small sacrifice in good times is more than offset by the gains in bad times, so regulation raises expected originator surplus.

There are two ways to increase the informational sensitivity of securities issued by originators. First, limiting the issuance of informationally insensitive debt in good times would raise the demand for informed capital to purchase equity in the primary market, increasing the returns to being informed. This would induce more investors to become informed ex ante and alleviate underfunding in bad times. Alternatively, constraining originators to issue riskier debt in good times would raise the adverse selection profits available to informed investors trading in the secondary market, again increasing the incentives to become informed ex ante. 
By contrast, in the private market equilibrium, each originator takes the information production infrastructure of investors as fixed. Each finds it privately optimal to issue informationally insensitive debt in good times. These decisions collectively reduce the supply of informationally sensitive securities that informed investors can profit from, dulling ex ante incentives to become informed and exacerbating the underfunding problem in bad times.

Why is the private market unable to overcome the financing friction on its own? The answer lies in two problems: a commitment problem and an externality. First, originators cannot commit to limiting their use of informationally insensitive debt in good times. Before it is known whether times will be good or bad, originators recognize that they would benefit from additional information infrastructure if the bad state occurs. From this ex ante perspective, originators would like to commit to issuing securities that encourage investors to become informed. However, once the good state is realized, originators maximize their profits by issuing large amounts of informationally insensitive debt. Anticipating originator behavior, investors limit their up-front investment in information infrastructure.

The second problem is an externality. An individual originator who issued informationally sensitive securities in good times would induce investors to build additional information infrastructure ex ante. However, that particular originator would not necessarily receive funding from informed investors in bad times. Thus, infrastructure is a public good from the perspective of originators: it has diffuse costs in good times and concentrated (rival and non-excludable) benefits in bad times. As a result, it is optimal for originators to avoid the higher costs of issuing informationally sensitive securities to informed investors in good times. Inefficient underfunding of loan pools in bad times can arise if either the commitment problem or the externality exists.

The assumption that information infrastructure, once endogenously chosen by investors, is fixed in the short term is crucial. Neither problem would exist if investors could make statecontingent infrastructure decisions. The assumption that infrastructure is fixed in the short run captures two ideas. First, financial capital may be slow-moving, so it might take time for informed investors to raise capital in bad times. Second, it takes time and resources to build new analytical capabilities, so uninformed investors cannot easily become informed in bad times.

The mechanism in our model is not the fire-sales channel of Diamond and Rajan (2011), Shleifer and Vishny (2010), and Stein (2012). While fire sales no doubt play an important role in many market breakdowns, our model emphasizes a different channel. In our model, the collapse of the primary market for securitizations is not due to attractive investment opportunities in the secondary market or anticipation of such opportunities in the future. Instead, it is driven by a "buyers' strike" among the uninformed investors upon whom the primary market normally relies. These uninformed investors simply move to the sidelines in bad times because they fear adverse selection and lack the infrastructure necessary to produce information about asset cash flows. 
Thus, unlike fire-sales models, where the capital structure decisions of leveraged investors may create externalities, in our model the capital structure decisions of originators themselves are the problem. As a result, our model suggests that policies designed to limit fire sales, like haircut regulation, may not be sufficient to reduce the fragility of securitization markets. It may also be desirable to regulate the capital structures of securitization trusts by limiting the amount of AAA-rated debt that can be issued in good times.

Our paper sits at the intersection of the literatures on security design and endogenous information acquisition. Much of the security design and optimal capital structure literature, including Myers and Majluf (1984), Gorton and Pennacchi (1990), Duffie and DeMarzo (1999), Bolton and Freixas (2000), DeMarzo (2005), Dang, Gorton, and Holmstrom (2010), Chelma and Hennessy (2010), and Pagano and Volpin (2010), takes investor composition as given and focuses on minimizing the costs of adverse selection. In contrast, we consider the effects of security design on the ex ante information infrastructure decisions of investors. In this regard, our work is related to the literature on endogenous participation, including Grossman and Stiglitz (1980), Merton (1987), Allen and Gale (1994), and Boot and Thakor (1997).

Moreover, in previous work the benefit provided by informed investors is typically an improvement in the real investment decisions of firms. In contrast, we highlight a novel benefit of informed investors: they are a robust source of capital capable of analyzing investment opportunities and financing positive NPV projects even in bad times. In our model the privately optimal capital structure decisions of issuers may endongenously result in an inefficient shortage of information infrastructure.

This also distinguishes our paper from the recent work of Coval, Jurek, and Stafford (2009a,b) and Gennaioli, Shleifer, and Vishny (2011), who argue that neglected risks explain the collapse of securitization markets in recent years. In contrast, we emphasize how financial innovations that create near-riskless securities encourage investors to rationally choose to be uninformed. Our results suggest that learning from prior mistakes will not necessarily eliminate the instabilities associated with near-riskless securities.

The paper is organized as follows. In section 2, we present the basic idea by sketching the outlines of the model. Section 3 presents the full model, solving for the private market equilibrium and the social planner's solution. Section 4 discusses the distinctive empirical implications of our model. Section 5 concludes. An Internet Appendix accompanying this paper contains several extensions and descriptions of several past instances of shutdowns in markets for near-riskless securities.

\section{The Basic Idea}

In this section we highlight the key message of the paper using a simplified outline of the model, which abstracts from the informational asymmetries that underpin the model and presents the basic inefficiency in reduced form. There are continuums of two types of agents: originators 
and investors. There are two periods, $t=0,1$. Investors make their information infrastructure decisions at $t=0$. At $t=1$, one of two possible states $S \in\{L, H\}$ (low or high) will be realized and then originators will try to raise financing for projects. The probability that the state is high is $\operatorname{Pr}[S=H]=p$.

The continuum of originators has unit mass. Each originator has zero wealth and has access to an indivisible project that requires an investment of $\$ 1$ at $t=1$. The expected value of projects is $V_{S}$ in state $S$ and we assume $V_{H}>V_{L}>1$-i.e., projects are more attractive in the $H$ state but are still positive NPV in the $L$ state.

There is an infinite mass of investors. If they wish to be informed $t=1$, investors must pay an infrastructure cost $c$ at $t=0$. The finite mass of investors who choose to become informed is denoted $K . K$ is the key endogenous variable to be determined in equilibrium. Critically, the number of informed investors is chosen at $t=0$ and cannot be conditioned on the realization of the state $S$ at $t=1$.

Being informed allows investors to capture rents from originators. Once the state $S$ has been realized at $t=1$, originators try to raise capital from investors. To raise financing, each originator makes a capital structure decision $d_{S}$ that results in a state-dependent transfer $\Pi_{S}\left(d_{S}\right)$ to informed investors. In the full model, these transfers are generated by ModiglianiMiller (1958) violations arising from asymmetric information, which allow informed investors to capture part of the project surplus from originators. Here we simply take $\Pi_{S}\left(d_{S}\right)$ as given. The total payoff of originators in state $S$ is $V_{S}-1-\Pi_{S}\left(d_{S}\right)$. Obviously, originators choose $d_{S}^{*}=\arg \min \Pi_{S}\left(d_{S}\right)$ to minimize the transfers. For simplicity, we assume that $\Pi_{S}(d)$ is a convex function so the optimal capital structure $d_{S}^{*}$ satisfies $\Pi_{S}^{\prime}\left(d_{S}^{*}\right)=0$.

Finally, assume that originators must raise some financing from informed investors, implying that the number of projects can be limited by the mass of informed investors, $K$. In particular, assume that all projects will be undertaken in the high state $(S=H)$ but that only fraction $N_{L}(K) \leq 1$ of projects will be undertaken in the $L$ state. This assumption captures the idea that informed investors are a robust source of capital, able to provide financing in the $L$ state but in limited supply, and we show that it holds in the full model in Section 3. Naturally, we have $N_{L}^{\prime}(K)>0$ so more projects are undertaken in the low state at $t=1$ when there are more informed investors.

\subsection{Private Market Equilibrium}

In the private market equilibrium, the mass of investors, $K^{*}$, who choose to become informed is pinned down by the following zero profit condition

$$
c K^{*}=p \cdot \Pi_{H}\left(d_{H}^{*}\right)+(1-p) \cdot \Pi_{L}\left(d_{L}^{*}\right) \cdot N_{L}\left(K^{*}\right)
$$


which must hold from an ex ante $(t=0)$ perspective. $\Pi_{S}\left(d_{S}^{*}\right)$ is the transfer from originators to informed investors per project that is funded in state $S$, so aggregate transfers in state $S$ are equal to the number of projects undertaken times $\Pi_{S}\left(d_{S}^{*}\right)$. The ex ante welfare of originators is

$$
W=p\left(V_{H}-1-\Pi_{H}\left(d_{H}^{*}\right)\right)+(1-p)\left(V_{L}-1-\Pi_{L}\left(d_{L}^{*}\right)\right) N_{L}\left(K^{*}\right) .
$$

Using the zero profit condition of investors, we can rewrite this as

$$
W=p\left(V_{H}-1\right)+(1-p)\left(V_{L}-1\right) N_{L}\left(K^{*}\right)-c K^{*}
$$

Originators bear the full information infrastructure costs of investors since investors earn zero profits. As a result, all that matters from the ex ante perspective of originators is the probability of obtaining funding in the bad state, $N_{L}(K)$, and the total information cost incurred by investors, $c K$.

\subsection{The Planner's Intervention}

Can a planner improve on the private market outcome? Consider interventions that alter $H$ state capital structure decisions $d_{H}$ while holding $L$-state decisions fixed at $d_{L}=d_{L}^{*}$. The planner recognizes that such interventions can increase the number of informed investors in the market. Intuitively, originators pick $d_{H}^{*}$ to minimize their transfer to investors $\Pi_{H}\left(d_{H}\right)$. So by changing $d_{H}$ in either direction, the planner increases total transfers to informed investors. This boosts the incentive to become informed ex ante.

Formally, for a given level of $d_{H}$ the equilibrium number of informed investors $K^{*}$ satisfies the zero profit condition: $p \cdot \Pi_{H}\left(d_{H}\right)+(1-p) \cdot \Pi_{L}\left(d_{L}^{*}\right) \cdot N_{L}\left(K^{*}\right)=c K^{*}$. Thus, changing $d_{H}$ changes the number of informed investors by

$$
\frac{\partial K^{*}}{\partial d_{H}}=\frac{p \cdot \Pi_{H}^{\prime}\left(d_{H}\right)}{c-(1-p) \cdot \Pi_{L}\left(d_{L}^{*}\right) \cdot N_{L}^{\prime}\left(K^{*}\right)} .
$$

Under the assumption that $c>(1-p) \cdot \Pi_{L}\left(d_{L}^{*}\right) \cdot N_{L}^{\prime}\left(K^{*}\right)$, we have $\partial K^{*} / \partial d_{H}<0$ for $d_{H}<d_{H}^{*}$ and $\partial K^{*} / \partial d_{H}>0$ for $d_{H}>d_{H}^{*}$ because $\Pi_{H}\left(d_{H}\right)$ is convex and is minimized when $d_{H}=d_{H}^{*}$. In other words, more investors will become informed at $t=0$ as the planner either raises $d_{H}$ above $d_{H}^{*}$ or lowers $d_{H}$ below $d_{H}^{*}$.

How does such an intervention impact the ex ante welfare of originators? We have

$$
\frac{\partial W}{\partial K^{*}}=(1-p)\left(V_{L}-1\right) N_{L}^{\prime}\left(K^{*}\right)-c .
$$

The marginal benefit of having more informed investors is that $N_{L}^{\prime}\left(K^{*}\right)$ more projects, which each generate surplus $V_{L}-1$, are financed in the low state, which occurs with probability $(1-p)$. The marginal cost of having more informed investors is $c$. If $(1-p)\left(V_{L}-1\right) N_{L}^{\prime}\left(K^{*}\right)>c$, the 
planner can raise welfare by increasing the number of investors who choose to become informed. ${ }^{2}$ This can be achieved by either lowering $d_{H}$ below $d_{H}^{*}$ or by raising $d_{H}$ above $d_{H}^{*}$, since either intervention increases total transfers to informed investors.

\subsection{Core Intuition}

This simplified outline captures the core intuitions of the full model presented below. There is an endogenous lack of information production, which is driven by the capital structure decisions of originators. The key is that originators ultimately bear the information production costs of investors through the transfers $\Pi_{S}\left(d_{S}\right)$ they pick in each state. In the private market equilibrium, individual originators seek to minimize these transfers. The planner can raise ex ante originator welfare because of a pair of market failures: a commitment problem and an externality. The private market outcome can be inefficient if either market failure is present.

The commitment problem arises because originators choose their transfers after the state $S$ has been realized, but investors must decide to become informed before the state has been realized. At $t=0$, originators would like to commit themselves to larger transfers if the high state $S=H$ is realized. They understand that such a commitment would increase the number of informed investors and thus the probability of receiving financing if the low state is realized. But once the high state is realized, originators maximize profits by minimizing their transfers to investors, $\Pi_{H}\left(d_{H}\right)$. Investors anticipate this behavior and decline to become informed at $t=0$. Essentially, there is a market-wide version of the hold-up problem of Hart and Moore (1988).

The externality in the private market arises even if originators can commit at $t=0$ to statecontingent capital structure choices $d_{H}$ and $d_{L}$ at $t=1$. Since each originator is infinitesmal, each takes the aggregate transfer to informed investors as fixed. Therefore, each individual originator has no control over the number of informed investors in the market, $K$, and cannot affect his probability of receiving financing in the low state, $N_{L}(K)$. However, when aggregated up, the transfer decisions of individual originators determine the number of informed investors in the market. Intuitively, there is a tragedy of the commons. Each originator recognizes that he would benefit from the presence of additional informed investors, which could be achieved by additional high-state transfers $\Pi_{H}$. However, each originator hopes to minimize his share of these transfers. This tragedy of the commons endogenously leads to an inefficiently low number of informed investors.

More generally, if individual originators are small but not infinitesimal, the externality still exists. The probability of receiving financing in the low state would vary with the $d_{H}$ chosen by an individual originator. However, it varies less from an individual originator's perspective

\footnotetext{
${ }^{2}$ This condition embeds the financing friction necessary to generate inefficiency. To simultaneously have $(1-p)\left(V_{L}-1\right) N_{L}^{\prime}\left(K^{*}\right)>c$ and $c>(1-p) \cdot \Pi_{L}\left(d_{L}^{*}\right) \cdot N_{L}^{\prime}\left(K^{*}\right)$, we must have $\Pi_{S}(d)<V_{S}-1$ for all $d$, so that full surplus of projects cannot be transferred to informed investors. The importance of the financing friction will become clearer in the full model where $\Pi$ is determined in equilibrium.
} 
than it does from the planner's perspective. The intuition is that if an individual originator could precommit to a different $d_{H}$, the benefits of that decision (higher $K$ and more loan pools funded in the low state) cannot be promised exclusively to that particular originator: some benefits will accrue to others so the tragedy of the commons problem still exists. Only a monopolist originator would not suffer from this problem, although a monopolist would still face the commitment problem discussed above.

What is the assumed form of market incompleteness that gives rise to these two problems? To solve both problems, we would need to introduce "bilateral standby commitments" at $t=0$ that would commit a particular informed investor to provide financing to a particular originator if the low state occurs at $t=1$ and the originator is rationed. By its very nature, such a bilateral contract would solve the externality problem - if a particular informed investor can commit capital to particular originator ex ante, then informed capital is no longer a public good from originators' perspective.

Critically, this contract would also need to commit the originator to provide the informed investor with state-contingent transfers at $t=1$. The financing friction-i.e., the fact that the originator cannot pledge the full surplus of the project-means that it is insufficient to guarantee the informed investor high returns in exchange for financing in only the low state. The contract must also guarantee the informed investor some positive transfer in the high state. Such contracts, similar in some respects to bank loan commitments, are typically outside the scope of the anonymous, arm's length securities markets, and were not a prominent feature of the market for securitizations in the mid-2000s. As intermediation moves outside of the traditional banking sector, which often relies on these kinds of billateral contracts, and into markets, it becomes subject to the problems we highlight in this paper.

Interventions by a planner can solve both of these problems by pre-committing originators to a given transfer policy ex ante and by forcing all originators to participate. The planner effectively acts as a monopolistic originator with a commitment device.

\subsection{Relation to Full Model}

This simplified outline illustrates the core intuitions of the paper. The full model provides specific microfoundations to flesh out the skeleton presented here, focusing particularly on two points. First, we provide a microfoundation for the idea that originators control their transfers to informed investors through their security design decisions. This result is well-established in the literature. Specifically, Myers and Majluf (1984), Boot and Thakor (1993), Duffie and DeMarzo (1999), and many others argue that minimizing adverse selection is a key purpose of security design.

Second, the full model demonstrates how the limited capital of informed investors may constrain the financing of positive NPV projects. This is related to the literature on credit rationing (Stiglitz and Weiss (1981)), which shows that information asymmetries can result in 
positive NPV projects going unfunded. Specifically, in the bad state of our model, it is not possible to raise sufficient financing from uninformed investors due to the threat of adverse selection. Informed investors are not subject to adverse selection concerns and, hence, are a robust source of capital that alleviates underfunding in bad times. Our main contribution is to show that private optimizing originators will design their securities in a manner that blunts investor incentives to become informed. The resulting endogenous shortage of informed investors leads to inefficient rationing in bad times.

\section{Model}

In this section, we present the full model. Section 3.1. describes the setup of the full model and discusses our key modeling assumption that information production infrastructure is fixed in the short run. In Section 3.2, we solve for the private market equilibrium. Section 3.3 derives the planner's solution, which involves increasing the amount of informationally sensitive securities issued in good times, and explains the forces that generate the inefficiency of the private market outcome. Section 3.4 considers optimal interventions when the planner can both limit the issuance of safe securities in good times and guarantee debt in bad times.

\subsection{Setup}

The full model has 4 periods $(t=0,1,2,3)$ and three types of risk-neutral agents: originators, investors, and market makers. As in the simplified model, there is a continuum of measure 1 of originators. Each is endowed with the opportunity to originate a pool of loans at time 1, but has no capital. Loan pools are indivisible, and originating a loan pool requires $\$ 1$ of financing. To raise this financing, originators tranche the cash flows from their pools into senior debt claims and junior equity claims. They then attempt to raise $\$ 1$ by selling some or all of these claims to investors, retaining the rights to any residual cash flows.

Loan pool payoffs are realized at time 3. Payoffs depend on the state of the macroeconomy, which is common across all pools, and the quality or type of the individual pool, which is idiosyncratic. At $t=1$, when loan pools are originated, the state of the macroeconomy is common knowledge to originators and all investors, but the types of individual loan pools are unknown. Asymmetric information about individual loan pools is the key driving force in the model.

As before, the state of the macroeconomy is $S \in\{H, L\}$ (high or low), and the probability that the high state occurs at $t=1$ is $\operatorname{Pr}[S=H]=p$. Individual pools are either of good or bad quality, denoted by $Q \in\{G, B\}$, and the fraction of good pools is $\operatorname{Pr}[Q=G]=\theta$ in both states. Good pools pay $v^{G}>1$ regardless of the state. By contrast, bad pools pay $v_{H}^{B}<1$ in the high state and $v_{L}^{B}<v_{H}^{B}$ in the low state. We think of the payoff on bad pools in the high state, $v_{H}^{B}$, as being relatively close to 1 . The idea is that loan pools are very safe in good times because 
the idiosyncratic default risk of individual loans is diversified away and systematic default risk is minimal in the high state. ${ }^{3}$

The only difference between the high state and the low state is that bad pools have worse payoffs in the low state. This increases the scope for adverse selection in the low state. Let $V_{S}=\theta v^{G}+(1-\theta) v_{S}^{B}$ denote the expected value of the average loan pool in state $S$. We assume that $V_{H}>V_{L}>1$ so that funding loan pools is positive NPV even in the low state. Note that this assumption means that, in contrast to much of the existing literature, information production does not affect the quality of the projects undertaken. Since funding loan pools is positive NPV in both states of the world, zero information production would be the best outcome, a point emphasized by Dang, Gorton, and Holmstrom (2010). However, as we show below, information production has indirect social value in the model: the presence of informed capital increases the quantity of projects that can be financed in bad times which raises total originator surplus. Essentially, informed capital helps to solve a credit rationing problem in bad times. This setup enables us to emphasize the indirect "market robustness" value of informed capital.

There is an infinite mass of investors. Each investor is initially identical and endowed with $\$ 1$ of capital. All investors have access to a riskless storage technology in each period that generates a net return of zero. At $t=0$, before the state $S$ is known, each investor may make an irreversible decision to become informed by paying cost $c$ to build information production infrastructure. In return for paying this cost, informed investors will learn the type of individual loan pools at $t=2$. That is, informed investors will be able to distinguish good loan pools that pay $v^{G}$ from bad loan pools that pay $v_{S}^{B}$ at $t=2$. The number of informed investors is a proxy for the total information production infrastructure in the market. The key assumption is that investors make an infrastructure decision at $t=0$ and that these choices cannot be conditioned on the realization of the state of the macroeconomy $S$ at $t=1$. This captures the idea that capital and information infrastructure are fixed in the short run.

The assumption that the amount of informed capital is fixed at $t=1$ also affects the returns informed investors are able to earn. When originators sell claims backed by their loan pools at $t=1$, they face a fixed number of informed investors. Therefore, as discussed further below, the relative scarcity of informed investors is a key determinant of the profits the informed earn in the primary market for equity.

At $t=2$, after loan pools have been originated and sold to investors, informed investors learn the quality of individual pools. This information is private, and uninformed investors do not learn the quality of individual pools until $t=3$. After individual loan pool types are revealed to the informed, fraction $\ell$ of both informed and uninformed investors are hit by liquidity shocks. These liquidity shocks force investors to trade, raising the possibility of adverse selection at $t=2$, which in turn impacts the prices that investors are willing to pay at $t=1$.

\footnotetext{
${ }^{3}$ This point is developed further in the Internet Appendix where we explain why our model is specifically geared towards securitization and not the capital structure choices of individual firms.
} 


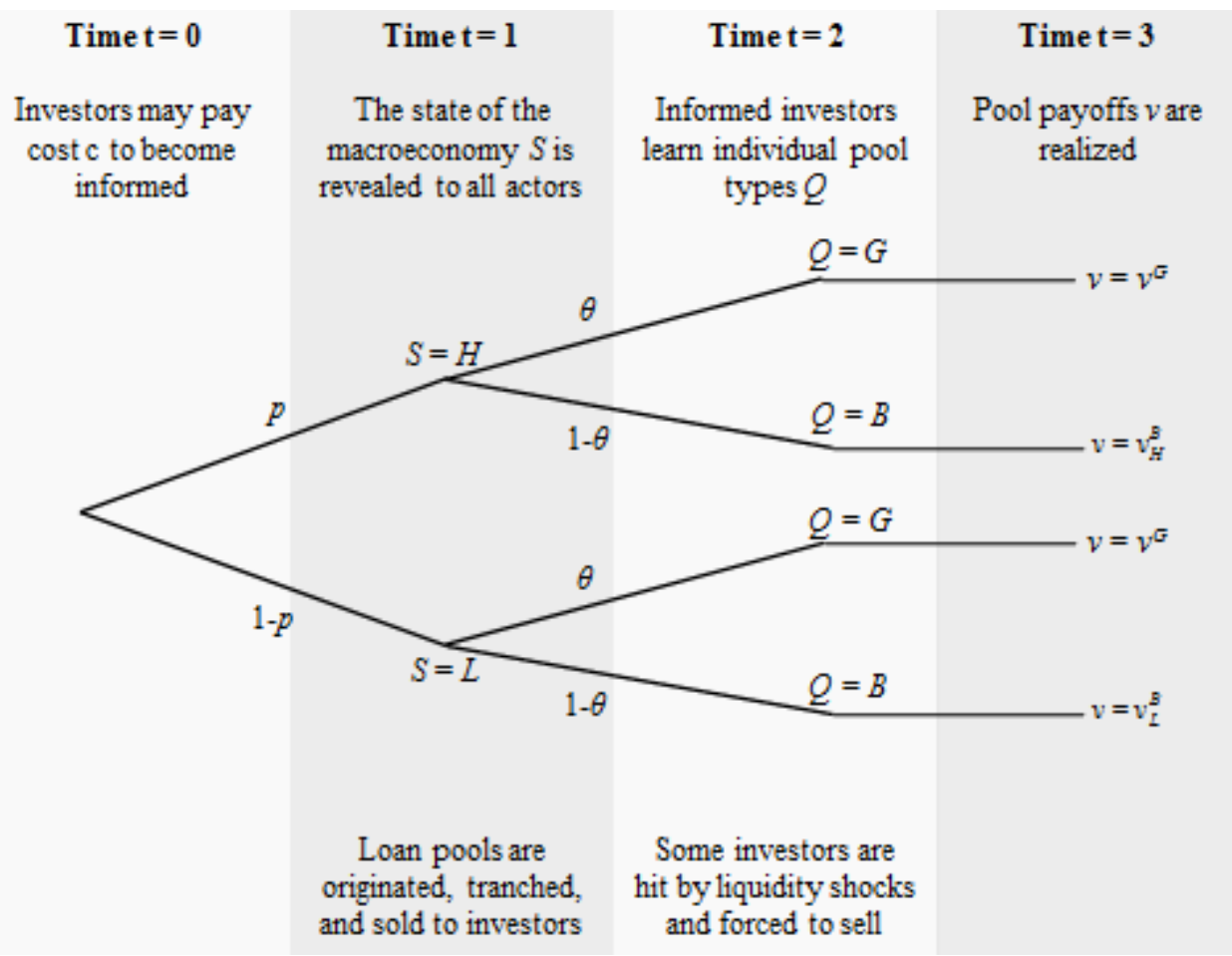

Figure 1: Structure of the Game.

Investors hit by liquidity shocks must sell their securities. In addition, informed investors may, in the aggregate, sell short $M$ units of debt per loan pool originated. Uninformed investors have no private information and therefore will not sell securities short in equilibrium. Short selling of debt by informed investors in the secondary market opens the door for adverse selection at $t=2$. Investors sell their securities to the third group of agents in the model, uninformed market makers. We assume these market makers have enough capital to buy all securities investors wish to sell at $t=2$. Prices in the secondary market will be pinned down by market makers' zero-profit condition.

Figure 1 summarizes the timing of the game. At $t=0$ investors choose whether or not to become informed. At $t=1$ the state of the macroeconomy is revealed to everyone. Originators then attempt to originate loan pools and sell claims backed by those cash flows to investors. At $t=2$, the quality of individual loan pools is revealed to informed investors. Some investors are then hit by liquidity shocks and sell securities to market makers. At $t=3$, payoffs are realized.

\subsubsection{What is Information Production Infrastructure?}

Information production infrastructure in the model can be thought of as market-specific information technology or human capital. As pointed out by Brunnermeier and Oehmke (2009) and Arora et al. (2009), analysis of securitizations is computationally complex. For an investment fund to produce information about specific securitizations, it must have a variety of databases 
and analytical tools, as well as a stock of human capital (i.e., analysts) familiar with these tools.

The assumption that the amount of informed capital is fixed in the short run is critical to our results and captures two natural ideas. First, financial capital is slow-moving following market shocks due to a variety of frictions (Duffie 2010). Specifically, it takes time to reallocate financial capital from delegated investors lacking information infrastructure to those with the necessary infrastructure. Informed investors may need several months to raise new funds, a significant amount of time for primary markets to be constrained.

Second, it takes time to build information infrastructure. Once an investment fund decides to build additional analytical capacity, it could take several months for that capacity to come online. Indeed, the American Securitization Forum (2008) recognized that this time-to-build problem was exacerbating the shutdown of the securitization market in late 2008, reporting that "The market faces significant challenges in developing new investors... Sources of new funds that could potentially be invested ... will need to find mechanisms to access the capabilities and infrastructure necessary to manage securitized products." In summary, the combination of slow-moving capital and a time-to-build problem for informational infrastructure means that the amount of informed capital may often be fixed in the short-run.

\subsection{Private Market Equilibrium}

We now construct the private market equilibrium. We start by considering the outcome of the secondary market trading game at $t=2$. We then fold this back into the prices that investors are willing to pay for securities at $t=1$. Taking these prices as given, we then consider the $t=1$ capital structure decisions of originators (i.e., the mix of debt and equity they use to finance loan pools). Finally, we consider the $t=0$ decisions of investors to become informed.

\subsubsection{Adverse Selection in the Time 2 Secondary Trading Game}

We begin with the trading game at $t=2$. The trading game raises the prospect of adverse selection by forcing uninformed investors to face informed investors in the secondary market. Suppose we are in state $S$ at $t=2$ and that originators have chosen to issue debt of face value $d_{S}$ at $t=1$. Furthermore, suppose that at the chosen value of $d_{S}$ informed investors choose to buy equity claims and uninformed investors choose to buy debt claims. In Appendix B we verify that this is indeed the case in equilibrium when $M$ is sufficiently large.

Recall that there is asymmetric information at $t=2$. Specifically, informed investors can distinguish good and bad loan pools, but uninformed investors and market makers cannot. There are two separate secondary markets, one where all debt securities are traded and one where all equity securities are traded. Prices in both markets are set by uninformed market makers to make zero profits on average. First consider the secondary market for debt. Fraction $\ell$ of uninformed investors will be hit by liquidity shocks and will be forced to sell their debt, 
which will be of average quality. In addition, all informed investors will short sell debt backed by bad pools, generating adverse selection in the market. ${ }^{4}$

We assume that informed investors can, in the aggregate, sell short $M$ units of debt per loan pool originated. A large $M$ indicates fewer impediments to short-selling. The market maker will set the $t=2$ price of debt, $P_{2}\left[D ; d_{S}\right]$, so that his profits from forced sellers exactly offset his losses to informed short sellers

$$
\underbrace{\ell\left(\theta \min \left\{v^{G}, d_{S}\right\}+(1-\theta) \min \left\{v_{S}^{B}, d_{S}\right\}-P_{2}\left[d_{S} ; D\right]\right)}_{\text {Profit from forced sales by the uninformed }}=\underbrace{M\left(P_{2}\left[d_{S} ; D\right]-\min \left\{v_{S}^{B}, d_{S}\right\}\right)}_{\text {Loss to informed }} .
$$

This implies that

$$
P_{2}\left[D ; d_{S}\right]=\underbrace{\theta \min \left\{v^{G}, d_{S}\right\}+(1-\theta) \min \left\{v_{S}^{B}, d_{S}\right\}}_{\text {Expected value }}-\underbrace{\theta \frac{M}{M+\ell}\left(\min \left\{v^{G}, d_{S}\right\}-\min \left\{v_{S}^{B}, d_{S}\right\}\right)}_{\text {Adverse selection discount }},
$$

so risky debt $\left(d_{S}>v_{S}^{B}\right)$ trades at a discount to its expected value in the secondary market.

Next consider the secondary market for equity. Informed investors who are hit by liquidity shocks are forced to sell their equity, regardless of the quality of the pool backing it. In addition, informed investors not hit by liquidity shocks will opportunistically sell their bad pools. For simplicity, we assume that informed investors are not able to borrow any additional equity to sell short, since all of the equity in bad pools is already being sold at $t=2$. This assumption is not critical but simplifies the analysis considerably. In the Internet Appendix, we show that our results continue to hold when we treat debt and equity symmetrically. ${ }^{5}$

The market maker sets the $t=2$ price of equity, $P_{2}\left[E ; d_{S}\right]$, such that

$$
\begin{aligned}
& \overbrace{\ell\left(\theta \max \left\{v^{G}-d_{S}, 0\right\}+(1-\theta) \max \left\{v_{S}^{B}-d_{S}, 0\right\}-P_{2}\left[d_{S} ; E\right]\right)}^{\text {Profit from forced sales }} \\
= & \underbrace{(1-\ell)(1-\theta)\left(P_{2}\left[d_{S} ; E\right]-\max \left\{v_{S}^{B}-d_{S}, 0\right\}\right)}_{\text {Loss from opportunistic sales }},
\end{aligned}
$$

\footnotetext{
${ }^{4}$ We make the standard assumption that market makers cannot identify investors as informed or uninformed and therefore cannot discriminate between forced sales and informed short sales.

${ }^{5}$ Specifically, in the Internet Appendix, we assume that short-selling is not allowed for either debt or equity. Instead, adverse selection on risky debt stems from the fact that informed investors choose to purchase some fraction of debt in the primary market at $t=1$. Because informed investors opportunistically sell risky debt backed by bad loan pools at $t=2$, debt trades at a discount at $t=2$. And because the uninformed are the marginal debt investors at $t=1$, this adverse selection discount is reflected in time 1 prices. In equilibrium, informed investors adjust their primary market purchases of debt and equity so that the scarcity returns on equity equal the adverse selection trading profits on risky debt.

In the main text, allowing the informed to short risky debt backed by bad pools is a simple modeling device that enables us to transparently capture the informational rent that informed investors extract. Specifically, by assuming that the informed can always short $M$ pools, we bypass the complexities of their optimal portfolio allocation problem. However, our results continue to hold when we do not make this simplifying assumption.
} 
which implies that

$$
\begin{aligned}
P_{2}\left[d_{S} ; E\right]= & \overbrace{\theta \max \left\{v^{G}-d_{S}, 0\right\}+(1-\theta) \max \left\{v_{S}^{B}-d_{S}, 0\right\}}^{\text {Expected value }} \\
& -\underbrace{\theta \frac{(1-\ell)(1-\theta)}{(1-\ell)(1-\theta)+\ell}\left(\max \left\{v^{G}-d_{S}, 0\right\}-\max \left\{v_{S}^{B}-d_{S}, 0\right\}\right)}_{\text {Adverse selection discount }} .
\end{aligned}
$$

Thus, both debt and equity trade at an adverse selection discount at $t=2$ due to opportunistic trading by informed investors.

\subsubsection{Security Prices and Capital Structure Decisions at Time 1}

Next consider the prices that informed and uninformed investors are willing to pay for securities at $t=1$. Recall that at $t=1$, the state of the macroeconomy is common knowledge, but the quality of individual loan pools are unknown to all agents. The uninformed anticipate that with probability $\ell$ they will be forced to sell at an unfavorable price at $t=2$. Therefore, they will charge an adverse selection discount at $t=1$, and the price of debt at $t=1$ is

$$
P\left[D ; d_{S}\right]=\overbrace{\theta \min \left\{v^{G}, d_{S}\right\}+(1-\theta) \min \left\{v_{S}^{B}, d_{S}\right\}}^{\text {Expected value }}-\overbrace{\theta \ell \frac{M}{M+\ell}\left(\min \left\{v^{G}, d_{S}\right\}-\min \left\{v_{S}^{B}, d_{S}\right\}\right)}^{\text {Expected loss from adverse selection when forced to sell }}
$$

The adverse selection discount simply compensates the uninformed for the expected wealth transfer to the informed in the secondary market at $t=2$.

While informed investors also suffer from adverse selection when hit by liquidity shocks, they benefit from their ability to adversely select others when they are not hit by liquidity shocks. The expected payoff to purchasing equity for informed investors is

$$
\begin{aligned}
& \overbrace{\theta(1-\ell) \max \left\{v^{G}-d_{S}, 0\right\}}^{\text {Good pool, no liquidity shock }}+\overbrace{\theta \ell P_{2}\left[d_{S} ; E\right]}^{\text {Good pool, forced sale }}+\overbrace{(1-\theta) P_{2}\left[d_{S} ; E\right]}^{\text {Bad pool }} \\
= & \theta \max \left\{v^{G}-d_{S}, 0\right\}+(1-\theta) \max \left\{v_{S}^{B}-d_{S}, 0\right\} .
\end{aligned}
$$

Since market makers make zero profits, adverse selection between informed investors simply transfers wealth between them and nets out in the aggregate. Thus, the expected payoff to purchasing equity for the informed is the fundamental value of the equity, and the informed do not need to charge an adverse selection discount at $t=1$.

However, recall there are a fixed number of informed investors at $t=1$. Therefore, the number of investors who become informed may be small enough that they can earn a positive rent based on their scarcity. ${ }^{6}$ Let the return earned per dollar invested by the informed in

\footnotetext{
${ }^{6}$ By contrast, there are an infinite number of uninformed investors in the primary market for debt and an infinite number of uninformed market makers in secondary markets. As a result, they are never scarce and
} 
state $S$ be $r_{S}$. $r_{S}$ is taken as fixed by originators, but in equilibrium it will be determined by the relative scarcity of informed capital as described in detail below. Thus, the price informed investors are willing to pay for equity claims at $t=1$ is given by

$$
P\left[d_{S} ; E\right]=\frac{\theta \max \left\{v^{G}-d_{S}, 0\right\}+(1-\theta) \max \left\{v_{S}^{B}-d_{S}, 0\right\}}{1+r_{S}}
$$

Thus, two opposing violations of the Modigliani-Miller (1958) theorem pin down an optimal capital structure. Debt suffers from an adverse selection discount, while originators perceive equity as expensive due to the scarcity return earned by informed investors. Note that both violations result in transfers from originators to informed investors, as assumed in the simplified model.

Originators pick the face value of debt $d_{S}$ to maximize the value of the stake they retain in the loan pool — or equivalently to minimize their transfer to the informed. ${ }^{7}$ Appendix B shows that originators' objective function can be written as

$$
\max _{d_{S}} P\left[d_{S} ; E\right]+P\left[d_{S} ; D\right]
$$

Figure 2 depicts this capital structure decision, plotting security prices as a function of $d_{S}$. The dotted blue line shows that the price of debt increases one-for-one with $d_{S}$ when $d_{S}<v_{S}^{B}$ because debt is risk-free in this range. When $d_{S}>v_{S}^{B}$, the debt is risky and its price increases at rate $\theta\left(1-\ell M(M+\ell)^{-1}\right)$, where $\theta$ reflects the debt's riskiness and $\left(1-\ell M(M+\ell)^{-1}\right)$ reflects the adverse selection discount charged by uninformed investors. The solid green line shows that the price of equity decreases with $d_{S}$, first at rate $-1 /\left(1+r_{S}\right)$ for $d_{S}<v_{S}^{B}$ and then at rate $-\theta /\left(1+r_{S}\right)$ for $d_{S}>v_{S}^{B}$.

Since $1>1 /\left(1+r_{S}\right)$, the value of equity decreases more slowly than the value of debt increases when the debt is risk-free $\left(d_{S}<v_{S}^{B}\right)$. Thus, originators always want to issue as much risk-free debt as possible to economize on costly informed capital. Would originators want to set $d_{S}>v_{S}^{B}$ and sell risky debt to uninformed investors? If

$$
\ell \frac{M}{M+\ell}>1-\frac{1}{1+r_{S}}
$$

the adverse selection discount charged by the uninformed for risky debt outweighs the higher rate of return charged by the informed. This condition holds when $\ell$ and $M$ are sufficiently large or $r_{S}$ is sufficiently small. When it holds, originators find it optimal to only issue risk-free debt, setting $d_{S}^{*}=v_{S}^{B}$. Note that $d_{L}^{*}=v_{L}^{B}<v_{H}^{B}=d_{H}^{*}$, so the originators' optimal capital structure involves more equity in the low state, when the scope for uninformed debt investors

always earn 0 return.

${ }^{7}$ The assumption that originators choose capital structures consisting only of debt and equity is without loss of generality. We would get the exact same results if originators issued debt to uninformed investors and some combination of risky junior debt and risky equity to informed investors. 


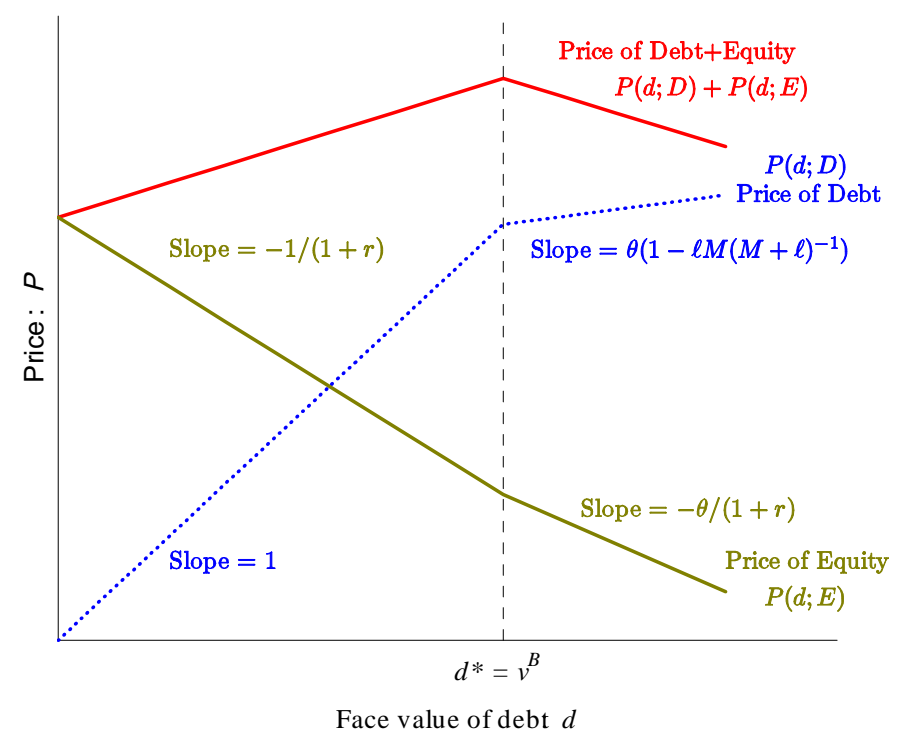

Figure 2: Originator Capital Structure Decisions.

to be adversely selected is higher.

The optimality of risk-free debt, which holds when (3) is satisfied, is a result of our assumption that loan pool payoffs are binary (either $v^{G}$ or $v_{S}^{B}$ ). In the Internet Appendix we develop a more general version of the model where pool payoffs are continuously distributed and show that originators find it optimal to issue debt that is slightly risky.

\subsubsection{Investor Decisions to Become Informed at Time 0}

Next we find the number of investors, $K$, who choose to become informed at time 0 . To do so, we first discuss how the return $r_{S}$ earned by informed investors in state $S$ is determined. The amount of equity financing originators attempt to raise from informed investors in state $S$ is $e_{S}=1-P\left[d_{S} ; D\right]$. We will say that informed capital is "maximally scarce" when it is fully invested in equity so that $K \leq e_{S}$.

As in any model with capital constraints, the fact that the amount of informed capital, $K$, is fixed at $t=1$ means that the relative scarcity of informed investors determines the returns they are able to earn. When informed investors are relatively abundant, originators can effectively hold them up, capturing most of the value of loan pools. Conversely, when informed investors are relatively scarce, they can capture more value from originators.

Formally, we write the return earned by the informed as a function of the supply and demand for informed capital: $r_{S}=r\left[K, e_{S}\right]$. In a "Walrasian" model of the interaction between originators and informed investors, $r[\cdot]$ takes a simple form. When informed investors are maximally scarce $\left(K \leq e_{S}\right)$, they capture as much of the value of loan pools as possible. When they are not maximally scarce $\left(K>e_{S}\right)$, they earn zero return.

To keep everything differentiable, we will not use the Walrasian model in the main text. 
Instead, we will assume that $r[\cdot]$ is smooth so that informed investors earn a positive return even when they are less than maximally scarce. As we show in Appendix A, this assumption can be micro-founded using a variant of the Rubinstein and Wolinsky (1985) bargaining model, in which originators must search for informed investors with whom they transact. ${ }^{8}$

The function $r[\cdot]$ determines the return earned by informed capital invested in equity. The following properties of the $r[\cdot]$ function will be used in the proofs:

1. Returns exceed $c$ when it is maximally scarce: $r\left[K, e_{S}\right]>c$ when $K \leq e_{S}$.

2. Informed capital earns a higher return when it is more scarce: $\partial r / \partial K<0$ and $\partial\left(r\left[K, e_{S}\right] \cdot e_{S}\right) / \partial e_{S}>$ 0 (i.e., total informed profit per pool, $r\left[K, e_{S}\right] \cdot e_{S}$, is increasing in the amount of equity originators attempt to raise).

3. Financing Friction: The full surplus associated with loan pools cannot be pledged to informed investors even when they are maximally scarce. Specifically, $r_{S} \cdot e_{S}<\left(V_{S}-1\right)$ where $V_{S}=\theta v^{G}+(1-\theta) v_{S}^{B}$ is the value of the average loan pool in state $S$.

The first property is an assumption. The second and third properties are microfounded in Appendix A. The first property states that it is possible for an informed investor to recoup her up-front infrastructure cost. The second property states that informed investors can extract more surplus from originators when informed capital is more scarce. This implies that the returns earned by informed investors are decreasing in the face value of debt. ${ }^{9}$

The third property is the key financing friction in the model. It drives a wedge between the private and social returns to informed capital, raising the possibility that the private market outcome may be inefficient. As shown in Appendix A, this property emerges naturally from the bargaining power of originators. Alternatively, it can be simply taken as an assumption motivated by moral hazard considerations outside the model. For instance, the originator may have to retain a stake in the loan pool to provide incentives for monitoring borrowers.

When informed capital is maximally scarce $\left(K \leq e_{S}\right)$, the number of pools that can be funded becomes constrained by the amount of informed capital available. Specifically, if capital is maximally scarce in state $S$ the number of projects that are funded is $N_{S}=K / e_{S} \leq 1$. This rationing outcome follows from the decentralized and sequential market structure inherent in any search model. The originators who encounter informed investors early transact, while those who do not are shut out of the market.

We can now analyze investor decisions to become informed at $t=0$. Informed investors must earn an average return of $c$ to break even. Thus, the equilibrium number of investors who

\footnotetext{
${ }^{8}$ This is effectively an extension of Nash bargaining to settings with continuums of agents. See Duffie, Garleanu, and Pedersen $(2005,2007)$ for further applications of bargaining models in financial markets. The assumption that $r[\cdot]$ is smooth is solely for expositional simplicity. In Appendix A we also show that one obtains identical results if the Walrasian model is used.

${ }^{9}$ To see this note that $\partial\left(r\left[K, e_{S}\right] \cdot e_{S}\right) / \partial d_{S}=-\left(\partial\left(r\left[K, e_{S}\right] \cdot e_{S}\right) / \partial e_{S}\right)\left(\partial P\left[d_{S} ; D\right] / \partial d_{S}\right)<0$.
} 
choose to become informed, $K^{*}$, satisfies the same zero profit condition as in the reduced-form model

$$
c K^{*}=p \cdot N_{H} \cdot \Pi_{H}\left[K^{*}, d_{H}^{*}\right]+(1-p) \cdot N_{L} \cdot \Pi_{L}\left[K^{*}, d_{L}^{*}\right]
$$

where $N_{S}=\min \left\{1, K^{*} / e_{S}^{*}\right\}$ is the number of loan pools originated in state $S$ and

$$
\Pi_{S}\left[K^{*}, d_{S}^{*}\right]=\underbrace{r\left[K^{*}, 1-P\left[d_{S}^{*} ; D\right]\right]\left(1-P\left[d_{S}^{*} ; D\right]\right)}_{\text {primary equity market scarcity profits }}+\underbrace{\frac{M}{M+\ell} \ell \theta\left(\min \left\{v^{G}, d_{S}^{*}\right\}-\min \left\{v_{S}^{B}, d_{S}^{*}\right\}\right)}_{\text {secondary debt market adverse selection profits }}
$$

is the profit earned by informed investors in state $S$ per pool originated. Informed investors can (in expectation) earn profits from two sources: their scarcity in the primary market for equity at time 1 and their trading in the secondary market for debt at time 2 . Recall that, in expectation, informed investors earn no adverse selection profits from trading in the secondary market for equity: sometimes they are hit by liquidity shocks and suffer losses due to adverse selection, while other times they are not hit by liquidity shocks and profit from their ability to opportunistically sell equity in bad pools.

We now find conditions under which $e_{H}^{*}<K^{*}<e_{L}^{*}$ (where $e_{S}^{*}=1-P\left[d_{S}^{*} ; D\right]$ ), so that there is enough informed capital to fund all loan pools in the high state but not enough to fund all loan pools in the low state. First, note that we must have $K^{*}>e_{H}^{*}$. Suppose the number of informed investors is $K \leq e_{H}^{*}$. Since $e_{H}^{*}<e_{L}^{*}$, informed investors would be maximally scarce in both states, and they would earn a return greater than $c$ in both states of the world by the first property of $r[\cdot]$. Thus, informed investors would earn positive profits and (4) would not be satisfied. More investors would choose to become informed so $K^{*}>e_{H}^{*}$.

Next suppose there are just enough informed investors to fund all loan pools in the low state $\left(K=e_{L}^{*}=1-P\left[d_{L}^{*} ; D\right]\right)$. If

$$
p \cdot \Pi_{H}\left[1-P\left[d_{L}^{*} ; D\right], d_{H}^{*}\right]+(1-p) \cdot \Pi_{L}\left[1-P\left[d_{L}^{*} ; D\right], d_{L}^{*}\right]<c\left(1-P\left[d_{L}^{*} ; D\right]\right),
$$

these informed investors do not earn enough to break even. Thus, assuming condition (6), we will have $e_{H}^{*}<K^{*}<e_{L}^{*}$.

These conditions simplify when condition (3) is satisfied, and originators choose to make the debt risk-free. Then $d_{S}^{*}=v_{S}^{B}$ and $e_{S}^{*}=1-v_{B}^{S}$, so there is no adverse selection in the secondary market for debt and the informed must fully recoup the costs of infrastructure by charging a scarcity premium in the primary market for equity. Condition (6) then reduces to

$$
p \cdot r\left[1-v_{L}^{B}, v_{H}^{B}\right] \frac{1-v_{H}^{B}}{1-v_{L}^{B}}+(1-p) \cdot r\left[1-v_{L}^{B}, v_{L}^{B}\right]<c,
$$

and the zero profit condition for informed investors is given by

$$
c K^{*}=p \cdot r\left[K^{*}, 1-v_{H}^{B}\right] \cdot\left(1-v_{H}^{B}\right)+(1-p) \cdot r\left[K^{*}, 1-v_{L}^{B}\right] \cdot K^{*} .
$$


We also must assume

$$
\theta v^{G}+(1-\theta) v_{L}^{B}-\theta \ell M(M+\ell)^{-1}\left(v^{G}-v_{L}^{B}\right)<1
$$

so originators who are unable to raise equity capital from informed investors cannot raise $\$ 1$ of financing using only debt capital from uninformed investors in the low state. That is, even if we set $d_{S}=v^{G}$ so that the debt is a claim on the entire value of the loan pool, uninformed investors will not provide $\$ 1$ of financing. Since $v_{L}^{B}<1$, this condition always holds if $\ell$ and/or $M$ are sufficiently large. Essentially, we are assuming that adverse selection problems are severe enough in bad times that uninformed investors are unwilling to provide enough financing to originate a loan pool without the participation of informed investors. The idea that concerns about adverse selection may prevent agents from undertaking positive NPV projects is well established in the literature on asymmetric information (see e.g., Stiglitz and Weiss (1981), Besanko and Thakor (1987), and Bernhardt (2000)). And, critically, equation (7) means that the amount of informed capital can be a binding constraint on loan pool origination in bad times.

The private market equilibrium of interest is summarized by the following proposition.

Proposition 1 Suppose that conditions (3), (6), and (7) are satisfied. Then the private market equilibrium is a triple $\left(K^{*}, d_{H}^{*}, d_{L}^{*}\right)$ such that: (i) originator capital structure decisions are optimal and $d_{S}^{*}=v_{S}^{B}$; (ii) the number of informed investors $K^{*}$ satisfies the zero-profit condition (4); and (iii) the number of loan pools originated is $N_{H}^{*}=1$ in the high state and $N_{L}^{*}=$ $K^{*} /\left(1-d_{L}^{*}\right)<1$ so that positive NPV loan pools go unfunded in the low state.

Proof. All proofs are presented in Appendix B.

Note that the severity of adverse selection, which is controlled by $M$ and $\ell$ in the model, is critical to equilibrium we construct. If $M$ is small enough that condition (3) does not hold, then originators always find it optimal to issue only risky debt to finance their loan pools (i.e. they will set $d_{S}>v_{S}^{B}$ such that $\left.P\left[d_{S}^{*} ; D\right]=1\right)$. They will be able to raise the full $\$ 1$ necessary to finance their loan pools in this manner because condition (7) will not hold when $M$ is small. Thus, adverse selection will never be bad enough to cause the collapse of the market. When (6) is not satisfied, enough investors become fully informed to fund all loan pools in the low state.

\subsubsection{Private Market Instability}

The private market equilibrium in the full model features a crash in issuance in the low state. Despite the fact that the average loan pool is positive NPV in the low state, it cannot be financed because uninformed investors are unwilling to provide funding. In equilibrium, originators sell as much risk-free debt as possible in both states of the world. They do this because tranching cash flows is valuable: it allows originators to economize on costly informed capital. However,

originators economize so much that they blunt incentives to become informed at time 0 . The 
amount of robust informed capital may be insufficient to finance all loan pools in bad times, and positive NPV loan pools go unfunded.

Informed capital is robust because even though informed investors who purchase equity sometimes suffer adverse selection when they are hit by liquidity shocks, they also profit from adverse selection when they are not hit by liquidity shocks. As a result, their willingness to participate in the primary issuance market does not decline when the scope for adverse selection declines in bad times. ${ }^{10}$

The nature of the private market equilibrium depends crucially on the fact that investor infrastructure decisions cannot be made state-contingent. To see this, suppose there were only a single state of the world. Then investors would be able to perfectly forecast demand for informed capital and enough investors would become informed to fund all loan pools.

Why ignorance may not be bliss One might wonder whether an "ignorance-is-bliss" (i.e., $K=0$ ) outcome, in the words of Dang, Gorton, and Holmstrom (2010), is possible in our setting. Since there is no direct social benefit of information production in our setting, a planner in our model would ideally want to prohibit all investors from building information infrastructure. However, in a more complicated model where informed investors also provide direct social benefits by improving the real investment decisions of firms (e.g., by screening out negative NPV projects) such a prohibition would be undesirable.

Furthermore, it would be difficult if not impossible to enforce such a prohibition. And if the planner cannot prevent investors from becoming informed, a $K=0$ equilibrium is not sustainable in our model. The key assumption that drives this result is that positive NPV loans pools require risky external finance (i.e., $v_{S}^{B}<1$ ). To see this, conjecture an equilibrium in which $K=0$ and all investors are uninformed. Since originators must raise $\$ 1$ of external finance, at least $1-v_{S}^{B}$ of it must be risky regardless of the form of the financing. As a result, adverse selection profits equal to $\ell M(M+\ell)^{-1}\left(1-v_{S}^{B}\right)$ are available in state $S$. Mass $K$ of investors could become informed and earn a return on capital of

$$
K^{-1} \frac{M \ell}{M+\ell}\left[p\left(1-v_{H}^{B}\right)+(1-p)\left(1-v_{L}^{B}\right)\right]
$$

which can be made larger than $c$ by taking $K$ small enough. Thus, some mass $K>0$ of investors will always choose to become informed. Once some investors become informed, market crashes due to adverse selection can occur because information infrastructure cannot be made state contingent. $^{11}$

\footnotetext{
${ }^{10}$ Indeed the fact that equity trades in our model is not critical to our results. We make this assumption for symmetry so that equity is subject to the same type of adverse selection problems that the debt is, which helps underscore our point that informed capital is robust capital.

${ }^{11}$ In contrast, in Dang, Gorton, and Holmstrom (2010) information production decisions can be made at any time. However, in their model symmetric ignorance dominates symmetric information. Trade is constrained by the cash-on-hand of patient agents when there is good news about asset values. Thus, it is better to trade
} 
The key point of our paper is then this: in a world where an ignorance-is-bliss equilibrium cannot be sustained, it may be optimal to encourage, rather than discourage, the entry of informed investors because these investors are a robust source of capital. As the next section shows, this objective can be achieved through capital structure regulation in good times.

\subsection{The Planner's Problem: Regulating Capital Structure}

We next turn to the social planner's problem. Our welfare criterion is total ex ante originator surplus, so we can either think of the planner simply as a coordinator trying to maximize the surplus of originators as a group. As in the simplified model, ex ante originator surplus is given by

$$
p N_{H}\left(V_{H}-1\right)+(1-p) N_{L}\left(V_{L}-1\right)-c K
$$

where $V_{S}=\theta v^{G}+(1-\theta) v_{S}^{B}$ is the expected value of loan pools in state $S$ and where $N_{S}$ in the number of loan pools originated in state $S$. As we discuss in Appendix B, since all investors earn zero profits, this quantity is also equivalent to combined ex ante surplus of originators and investors.

Could a social planner increase surplus by imposing ex ante restrictions on originator capital structure decisions in good times? We let the planner pick $d_{H}$ and let $K^{*}=K^{*}\left[d_{H}\right]$ be implicitly defined by the zero-profit condition of the informed (4). At the private market equilibrium we have $d_{H}=v_{H}^{B}, N_{H}=1$, and $N_{L}=K^{*}\left[d_{H}\right] /\left(1-v_{L}^{B}\right)$. Differentiating total surplus with respect to $d_{H}$ shows that the effect of altering $d_{H}$ consists of two parts:

$$
\underbrace{\left((1-p)\left(\frac{V_{L}-1}{1-v_{L}^{B}}\right)-c\right)} \frac{\partial K^{*}}{\partial d_{H}} .
$$

The first part is the social return to informed capital net of its cost. An extra unit of informed capital has cost $c$. The benefit of having this extra unit of informed capital is that it is a robust source of funding in the low state. The low state occurs with probability $(1-p)$, and an additional unit of capital can finance $1 /\left(1-v_{B}^{L}\right)$ more loan pools, each of which generates $V_{L}-1$ of surplus. When

$$
(1-p)\left(\frac{V_{L}-1}{1-v_{L}^{B}}\right)>c
$$

the social benefit of informed capital exceeds its cost. In this case, the planner would like to encourage more investors to become informed by creating more informationally sensitive securities, either lowering $d_{H}$ if $\partial K^{*} / \partial d_{H}<0$ or raising it if $\partial K^{*} / \partial d_{H}>0$. By contrast, if

without information production at the expected value of the asset than it is to trade with information production when the wealth constraint can become binding and limit trade. As a result, debt that induces zero information production is optimal in their model, not just because it eliminates adverse selection, but also because it reduces the variance of security prices. 


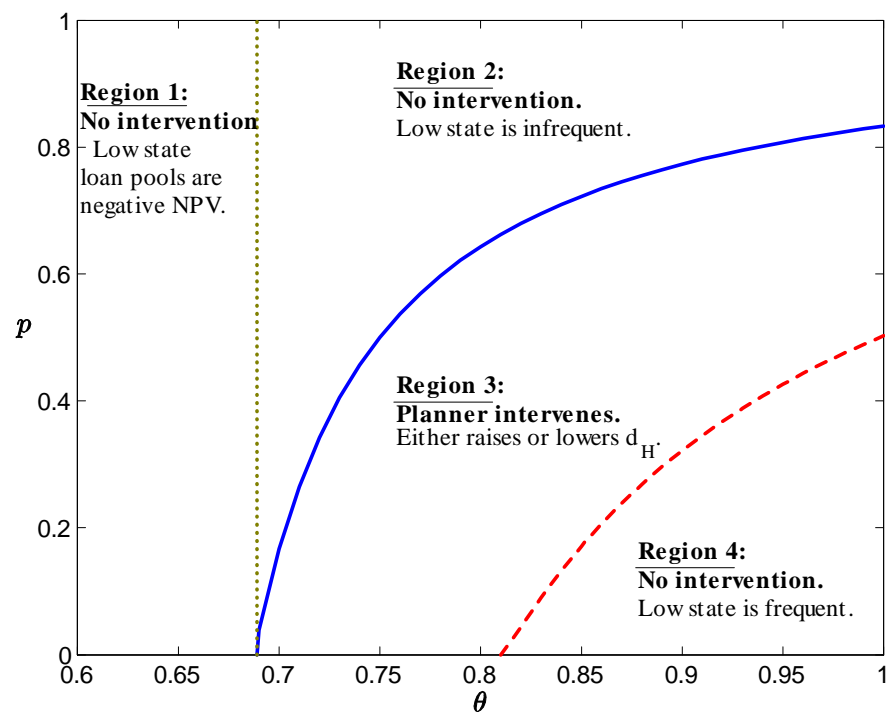

Figure 3: Model Behavior Varying the Frequency of the High State $p$ and the NPV of the Average Loan Pool $\theta$.

condition (8) does not hold, the planner would not want to pursue such interventions. ${ }^{12}$

Figure 3 illustrates the parameter values for which the planner would like to intervene to encourage more investors to become informed. It shows the effects of varying $\theta$, which controls the NPV of the average loan pool, and $p$, the frequency of the high state, while holding fixed all other parameters $\left(v^{G}, v_{L}^{B}, c\right.$, and $\left.w\right)$. The dashed red line corresponds to condition (6), while the solid blue line corresponds to condition (8). In Regions 1 and 2 the social benefit of additional informed capital does not outweigh its cost. In Region 1 many loan pools are bad ( $\theta$ is low), and in Region 2 the low state is infrequent ( $p$ is high). In Region 4 there is no underfunding in the private market equilibrium because enough investors become informed to fund all loan pools in the low state. In Region 3 there is socially inefficient underfunding in the private market equilibrium. In this region, the planner would regulate originator capital structure decisions in the high state.

How would the figure change if we modified the other parameters? Changes that increase the social benefit of loan pools (i.e., increasing $v^{G}$ or $v_{L}^{B}$ ) or decrease the cost of becoming informed $c$ shift the regional borders up and to the left. There would be fewer parameter values where underfunding is efficient and more parameter values where there is no underfunding. Increasing the size of the financing friction increases the area of Region 3, where underfunding is inefficient. Conversely, when there is no financing friction, Region 3 vanishes.

\footnotetext{
${ }^{12}$ Indeed, the planner may want to discourage investors from becoming informed. However, the planner's ability to restrict informed capital may be limited. As we argue below, lowering $d_{H}$ (relative to the private market equilibrium) always increases the amount of informed capital, while raising $d_{H}$ may either increase or decrease it. Thus, if (8) does not hold, the planner either wants to raise $d_{H}$ if that would lower the amount of informed capital, or she simply accepts the private market outcome as the constrained efficient outcome.
} 


\subsubsection{Planner's Interventions}

Since there are constant returns to loan pool origination, when condition (8) is met, the planner wants ensure that all loan pools are funded in the low state. How can she accomplish this? Two types of ex ante capital structure regulation could increase the number of informed investors. First, at time 0 the planner could announce a limit on the issuance of risk-free debt in the high state at time 1 . Second, at time 0 the planner could announce that the face value of debt in the high state at time 1 must be higher than in the private market equilibrium, increasing the riskiness of the debt. Both interventions effectively allow the planner to subsidize information production by increasing the amount of informationally sensitive securities from which informed investors can profit in good times.

First consider interventions that limit the issuance of risk-free debt in the high state (i.e., lower $d_{H}$ ). Intuitively, when $d_{H}<d_{H}^{*}=v_{H}^{B}$ the debt is risk-free so the informed earn no adverse selection profits in the secondary market; their only source of profits is primary market scarcity. Reducing the amount of risk-free debt issued increases the demand for informed capital in the primary market for equity. This increases the scarcity profits earned by the informed in the primary market and thus encourages more investors to become informed ex ante.

The planner can always use such interventions to ensure that all loan pools are funded in the low state. Specifically, the planner can limit high-state debt issuance to a value $d_{H}^{* *}$ such that $d_{L}^{*}<d_{H}^{* *}<d_{H}^{*}$ so enough investors become informed to fund all loan pools in the low state. Note that while the planner increases the number of informed investors, it is inefficient for all investors to be informed. She does not set $d_{H}^{* *}=0$ because securitization has social value in the model, reducing the number of investors who pay the infrastructure cost $c$. However, from the planner's perspective, the private market skimps too much on these costs.

Next consider interventions that increase the riskiness of debt in the high state by raising its face value (i.e., raising $d_{H}$ ). For $d_{H}>d_{H}^{*}=v_{H}^{B}$, the effect on the number of informed investors is ambiguous. Intuitively, once the planner perturbs $d_{H}$ so that the debt is slightly risky, the informed have two possible sources of profits: scarcity in the primary market for equity and adverse selection in the secondary market for debt. Raising $d_{H}$ lowers the demand for informed capital in the primary market for equity, reducing the scarcity profits. However, raising $d_{H}$ also increases the riskiness of the debt, increasing the adverse selection profits the informed can earn. The nature of primary market scarcity returns $r[\cdot]$ determines which effect dominates. In particular, if $\partial r_{H} / \partial d_{H}$ is not too negative, so that informed investors do not lose a large amount of primary equity market profits, raising the face value of debt increases the number of informed investors.

The planner's solutions are characterized in the following propositions.

Proposition 2 Suppose that conditions (3), (6), (7), and (8) are satisfied. Then the planner can increase total surplus by limiting debt issuance in the high state. This solution is given by the triple $\left(K^{* *}, d_{H}^{* *}, d_{L}^{* *}\right)$ such that: $(i) d_{L}^{* *}=d_{L}^{*}=v_{L}^{B}$ and the planner limits debt in the high 
state: $d_{H}^{* *}<d_{H}^{*}$; (ii) the number of informed investors is greater than in the private market outcome: $K^{* *}=K\left[d_{H}^{* *}\right]=1-d_{L}^{* *}>K^{*}$; and (iii) the number of projects undertaken is $N_{H}^{* *}=1$ in the high state and $N_{L}^{* *}=1$ so that there is no underfunding in the low state.

Proposition 3 Suppose that conditions (3), (6), (7), and (8) are satisfied. The planner may also be able to increase total surplus by requiring the debt issued in the high state to be riskier. In particular, if $\partial r_{H} / \partial d_{H}$ is not too negative, the planner can increase the number of informed investors by raising the high-state face value of debt $d_{H}$.

Policies limiting the issuance of safe securities raise the returns to informed investors and reduce originator profits in the high state, and thus represent an "in-kind" subsidy to informed investors. This subsidy can be achieved by either limiting the issuance of risk-free debt in the high state or by making all debt issued in the high state riskier. These are just two different ways of creating more informationally sensitive securities in normal times, which encourages more investors to build infrastructure.

Figure 4 illustrates this point graphically by showing total surplus achieved by the planner for various values of $d_{H}$ in a numerical example. The left panel shows that surplus is maximized when the planner sets $d_{H}=d_{H}^{* *}=\$ 0.56$ (the solid triangle) and fully funds all loan pools. Surplus is decreasing to the left of $d_{H}^{* *}$ : lowering $d_{H}$ in this range increases the demand for informed equity capital in the high state, but has no offsetting benefits because there is no underfunding in the low state to the left of $d_{H}^{* *}$. Tranching cash flows into junior and senior claims is valuable in the model. In its absence, too many investors would become informed. However, the private market economizes too much, and the planner can intervene to improve the outcome. Surplus is decreasing to the right of $d_{H}^{* *}$ because increasing $d_{H}$ reduces the demand for informed capital, resulting in fewer investors becoming informed and leading to underfunding in the low state.

The right panel shows that the planner can also achieve the maximal surplus by raising $d_{H}$. The private market equilibrium is given by $d_{H}=d_{H}^{*}=\$ 0.99$ (the solid circle) and the planner can achieve full funding in the low state by setting $d_{H}=d_{H}^{* *}=\$ 0.994$. Surplus decreases to the right of $d_{H}^{* *}$ because further raising $d_{H}$ increases the adverse selection profits available to informed investors in the secondary market, encouraging more investors than are necessary to fund all loan pools in the low state to become informed at time 0. Surplus decreases to the left of $d_{H}^{* *}$ because lowering $d_{H}$ reduces adverse selection profits, discouraging investors from becoming informed and creating underfunding in the low state.

\subsubsection{Private Market Inefficiency}

Note that the planner's solution can only differ from the private market equilibrium if informed investors cannot capture the full surplus of loan pools in the low state. Formally, if $r_{L}=$ $\left(V_{L}-1\right) /\left(1-v_{L}^{B}\right)$ when informed capital is maximally scarce, it is impossible to simultaneously 

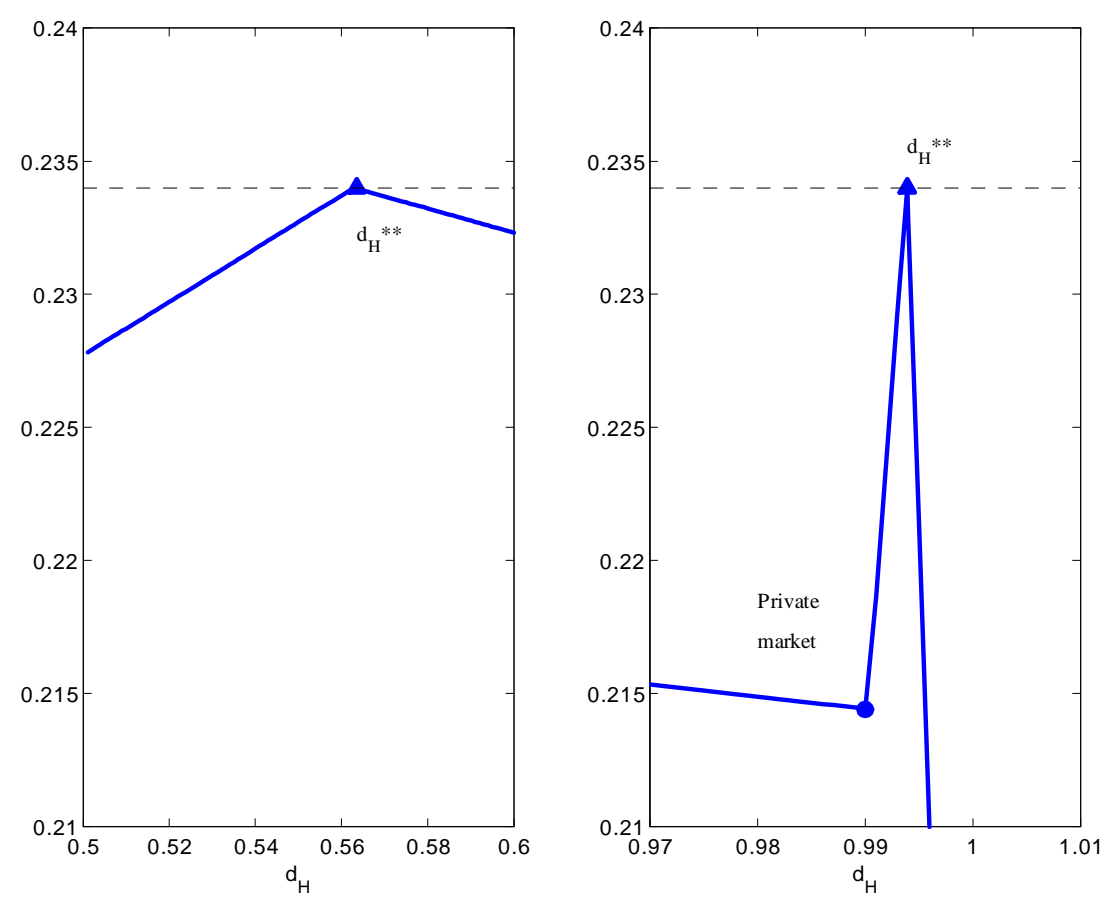

Figure 4: Surplus as a Function of High State Debt $d_{H}$.

satisfy conditions (6) and (8). Intuitively, if informed investors can capture the full surplus in the low state and this covers the costs of information infrastructure, then enough investors will become informed to ensure that all pools are financed in the low state.

The key contribution of our paper is to formalize why originators and investors are unable to overcome this financing friction themselves. Individual originators maximize their profits by minimizing the total transfer to informed investors. Raising as much risk-free debt as possible from the uninformed enables an individual originator to economize on costly informed capital. Each originator takes the number of informed investors as fixed, perceiving no costs offsetting this gain. By contrast, the planner is sensitive to the fact that originators' collective use riskfree debt in the high state affects the ex ante incentives of investors to become informed. Using more risk-free debt in the high state causes fewer investors to become informed and leads to greater underfunding in the low state. When condition (8) is met, the costs of underfunding in the low state outweigh the benefits of economizing on informed capital.

\subsection{The Planner's Problem: Debt Guarantees}

Beyond the ex ante capital structure regulations analyzed above, the planner could also try to increase the amount of debt financing used in the low state ex post. This would better leverage the fixed amount of informed capital available, increasing the number of loan pools it can be spread across. We consider an intervention where the planner can use debt guarantees, financed by distortionary taxes, to increase the amount of risk-free debt that originators can sell. The 
Term Asset-backed Securities Loan Facility (TALF) established by the Federal Reserve during the recent financial crisis essentially served this purpose, providing non-recourse leverage to sophisticated investors in securitizations.

The benefits of such loan guarantees is an increase in the number of loan pools financed in the low state. We assume that the costs of these guarantees are the distortions they create. Specifically the planner finances the guarantees with taxes, which create deadweight loss $\frac{1}{2} \gamma \tau^{2}$ when amount $\tau$ is raised. If the planner guarantees debt up to face value $d_{L}$, she will have to raise taxes to make a total of $\tau=(1-\theta)\left(d_{L}-v_{L}^{B}\right)$ in guarantee payments, resulting in a deadweight loss of $\frac{1}{2} \gamma(1-\theta)^{2}\left(d_{L}-v_{L}^{B}\right)^{2}$.

We continue to assume that condition (8) is met so that it is optimal for all loan pools to be financed in the low state. The planner first sets the optimal $d_{L}$ and then adjusts $d_{H}$ so that all loans pools can be financed in the low state (i.e., sets $d_{H}$ such that $K\left[d_{H}\right]=1-d_{L}$ ). Thus, the planner's objective function can be written as

$$
p\left(V_{H}-1\right)+(1-p)\left(V_{L}-1\right)-c\left(1-d_{L}\right)-\frac{1}{2}(1-p) \gamma(1-\theta)^{2}\left(d_{L}-v_{L}^{B}\right)^{2} .
$$

The planner trades off the costs of additional informed capital against the distortionary costs of debt guarantees. The optimal face value of guaranteed debt is given by

$$
d_{L}^{* * *}=v_{L}^{B}+\frac{c}{\gamma(1-p)(1-\theta)^{2}}
$$

The planner's solution can be summarized by the following proposition.

Proposition 4 Suppose that conditions (3), (6), (7), and (8) are satisfied. Then the planner's solution is a triple $\left(K^{* * *}, d_{H}^{* * *}, d_{L}^{* * *}\right)$ such that: (i) $d_{L}^{* * *}$ is given by (9); (ii) $K^{* * *}=1-d_{L}^{* * *}$; (iii) $d_{H}^{* * *}$ satisfies (4) given $K^{* * *}$ and $d_{L}^{* * *}$; and (iv) the number of projects undertaken is $N_{H}=1$ in the high state and $N_{L}=1$ in the low state.

Corollary 1 The planner's solution with debt guarantees approaches the planner's solution without guarantees as the distortionary costs of debt grow large: $\left(K^{* * *}, d_{H}^{* * *}, d_{L}^{* * *}\right) \rightarrow\left(K^{* *}, d_{H}^{* *}, d_{L}^{* *}\right)$ as $\gamma \rightarrow \infty$. Furthermore, there is a critical value $\bar{\gamma}$ such that for $\gamma>\bar{\gamma}$ the planner's solution involves a combination of debt limits and debt guarantees: $d_{H}^{* * *}<d_{H}^{*}$ and $K^{* * *}>K^{*}$.

The optimal level of guarantees equates the marginal deadweight cost of taxation with the marginal cost of additional informed capital, $c$. An important distinction between using guarantees ex post and regulating capital structure ex ante is that the costs of guarantees are only borne in the low state, whereas the costs of additional informed capital are borne unconditionally. Thus, ex post guarantees become more attractive as either $p \rightarrow 1$ so that crises are extremely rare or as $\theta \rightarrow 1$ so that guarantees are relatively inexpensive.

The planner always opts to guarantee some debt because there is no other taxation in this economy. Thus, regardless of the value of $\gamma$, the first dollar of taxation has marginal cost 0 
so that guarantees are initially quite appealing. In an economy where the level of taxation is already high, the planner might not opt to use any debt guarantees. The corollary notes that as taxation becomes increasingly expensive (i.e., as $\gamma$ increases), the planner will rely less on guarantees and more on altering $d_{H}$.

\section{Empirical Implications}

In addition to our model, several other explanations have been advanced for the collapse of securitization markets in the recent financial crisis. In this section, we discuss several empirical implications that distinguish the mechanism in our model from these alternative explanations. We also provide anecdotal evidence that our mechanism contributed to previous shutdowns of markets for near-riskless securities. ${ }^{13}$

\subsection{Fire Sales}

Explanations of the 2007-2008 collapse of securitization emphasizing fire sales have received significant attention in recent empirical and theoretical work. ${ }^{14}$ In fire-sale models, forced liquidations by leveraged investors create attractive investment opportunities in the secondary market, which draw capital away from the primary market. While forced liquidations are no doubt an important source of market disruptions, our model shows that they need not be the only source.

Fire-sale models imply very different patterns of securities holdings and flows among investors than our model. In particular, a key implication of the fire-sales view is that aggregate holdings should move from leveraged, sophisticated investors to unleveraged, unsophisticated investors over the course of the financial crisis. In contrast, our model suggests that informed investors should take on a bigger role in bad times as uninformed investors move to the sidelines. It would be possible to distinguish between these two contrasting views using data on the ABS holdings of various investor types through the crisis.

In practice, when markets for near-riskless securities shut down, anecdotal evidence suggests that uninformed investors tend to withdraw, not step in. For instance, in the recent crisis, the shutdown of the market for non-mortgage consumer credit (credit cards, auto loan, and student loan) securitizations was not driven by investor losses. Instead, as officials from the Federal Reserve described, "Investors became wary of all structured securities" because they were "complex and heterogeneous and, thus, hard to value" (Kohn 2009, Dudley 2009). Similarly, when the market for collateralized mortgage obligations (CMOs) collapsed in 1994,

\footnotetext{
${ }^{13}$ For more detail on these episodes, see the Internet Appendix.

${ }^{14}$ On the empirical side, see Gorton and Metrick (2010, 2011) and He, Khang, and Krishnamurthy (2010). On the theoretical side, see Brunnermeier and Pedersen (2009), Davila (2011), Geanakopolos (2009), Stein (2012), and Shleifer and Vishny (2010a,b).
} 
its demise was ascribed to uninformed investors who suddenly "[didn't] want to have anything to do with any structured mortgage product" (Carroll and Lappen 1994).

\subsection{Credit Ratings}

Another set of accounts of the recent financial crisis emphasize investor over-reliance on credit ratings. According to these accounts, many investors outsourced their credit analysis to the credit rating agencies prior to the crisis, but then lost faith in credit ratings as many AAAsecurities suffered downgrades in 2007 and 2008. Unable to analyze securities themselves, these investors simply withdrew from the market.

These accounts correspond closely to the mechanism in our model. Investors who outsource their analysis to rating agencies economize on the costs of information infrastructure, but withdraw from the market when they lose faith in the rating agencies in bad times. In this interpretation of the model, our results suggest that originators may rationally choose to issue large quantities of highly-rated securities to outsourcing investors in good times, even if they foresee the possibility that these investors will exit the market in bad times.

Problems with the credibility of credit ratings certainly played an important role in the recent crisis. According to Federal Reserve officials, when "inadequate rigor on the part of the rating agencies became apparent... an almost complete loss of investor appetite" resulted (Dudley 2009). In 2002, a similar dynamic had played out in the market for high-yield collateralized debt obligations (CDOs). This market grew rapidly in the late 1990s and early 2000s largely based on the participation of investors who did not "have the monitoring capabilities to track their investments, or infrastructure to examine them on a regular basis" (Pacelle and Zuckerman 2001). It then collapsed in the run-up to the Worldcom default in July 2002, as uninformed investors who did not have the ability to analyze CDOs withdrew once they lost faith in credit ratings.

\subsection{Neglected Risks}

Our model also has implications that distinguish it from accounts that emphasize neglected risks or mistakes by uninformed investors (see e.g., Coval, Jurek, and Stafford (2009a,b) and Gennaioli, Shleifer, and Vishny (2011)). Such accounts cannot explain recurring shutdowns in markets for near-riskless securities without appealing to recurring mistakes, which may be unlikely if sophisticated investors learn from mistakes. By contrast, our model suggests an externality that can lead to recurring breakdowns in markets for near-riskless assets. And while the recent financial crisis provides the most prominent example, markets for near-riskless securities have suffered numerous shutdowns in the last 40 years, including the collapses of the high-yield CDO market in 2002 and the CMO market in 1994 as described above, as well as the runs on asset-backed commercial paper market in 2007 and the nonfinancial commercial paper market after the Penn Central default in 1970. 
Identifying a clear market failure and regulations to address it is an important step in terms of normative analysis. However, it is not our intention to suggest that mistakes did not play a role in the recent crisis. Indeed, if uninformed investors neglect certain risks in normal times, this would likely exacerbate the basic inefficiency in our model. Specifically, such mispricing would make financing from uninformed investors even more attractive to issuers in good times, leading to even greater underinvestment in information infrastructure by investors.

\section{Conclusion}

We present a model in which too many informationally insensitive securities are issued in good times. The model has two key ingredients. First, there is a wedge between the social and private returns to information production infrastructure. Second, the information infrastructure of investors is fixed in the short run.

When combined, these ingredients result in a world where individual originators rationally economize on financing costs in good times by issuing large amounts of informationally insensitive securities to uninformed investors. This reduces the returns that informed investors earn in good times, endogenously resulting in a lack of information production infrastructure. In bad times when the amount of financing that can be raised from uninformed investors drops, there may be insufficient informed capital, and positive NPV loans may go unfunded. Securitization is valuable in helping to economize on information production costs, but the private market goes too far, resulting in a market that is overly fragile.

Thus, our model suggests that it might be desirable to regulate the capital structures of securitization trusts. Similar to bank capital requirements, such regulation might stipulate that no more than $50 \%$ of the securities backed by a given pool could be rated AAA or AA. This might be done by having AAA-rated senior debt comprise less than $50 \%$ of the pool and making the next tranche large enough so that it is rated below AA. This would correspond to the planner lowering $d_{H}$ in our model. Alternatively, the senior-most tranche could be very large so that it is rated below AA, which would correspond to the planner raising $d_{H}$ in the model.

More broadly, our approach highlights that the infrastructure and organization of professional investors is in part determined by the menu of securities offered by originators. Since robust infrastructure is a public good from the standpoint of originators, it may be underprovided in the private market equilibrium. The individually rational decisions of originators may lead to an infrastructure that is overly prone to disruptions in bad times. Policies regulating originator capital structure decisions may help promote a more robust market infrastructure. 


\section{References}

Allen, Franklin and Douglas Gale. "Limited Participation and Volatility of Asset Prices," American Economic Review, Vol. 84, No. 4 (Sep., 1994), pp. 933-955.

Arora, Sanjeev, Boaz Barak, Markus Brunnermeier, and Rong Ge. "Computational Complexity and Information Asymmetry in Financial Products," working paper, 2009.

Bernhardt, Dan, "Credit Rationing?," American Economic Review, Vol. 90, No. 1 (Mar., 2000), pp. 235-239.

Besanko, David and Anjan V. Thakor, "Competitive Equilibrium in the Credit Market under Asymmetric Information," Journal of Economic Theory, Vol. 42, No. 1 (June, 1987), pp. 167-182.

Boot, Arnoud W. A. and Anjan V.Thakor, "Security Design," Journal of Finance, Vol. 48, No. 4 (Sept., 1993), pp. 1349-1378.

Boot, Arnould and Anjan Thakor. "Financial System Architecture," Review of Financial Studies, 1997, 10(3), 693-733.

Bolton, Patrick and Xavier Freixas. "Equity, Bonds, and Bank Debt: Capital Structure and Financial Market Equilibrium Under Asymmetric Information," The Journal of Political Economy, Vol. 108, No. 2 (Apr., 2000), pp. 324-351.

Brunnermeier, Markus and Martin Oehmke. "Complexity in Financial Markets," working paper, 2009.

Brunnermeier, Markus and Lasse Pedersen. "Market Liquidity and Funding Liquidity," Review of Financial Studies, 2009, 22 (6), 2201-2199.

Carroll, Michael and Alyssa Lappen. "Mortgage-backed Mayhem," Institutional Investor, July 1994.

Chelma, Gilles and Christopher Hennessy. "Privately Optimal Securitization and Publicly Suboptimal Risk Sharing," CEPR working paper, 2010.

Coval, Joshua D., Jakub W. Jurek, and Erik Stafford. "Economic Catastrophe Bonds," American Economic Review 99, no. 3 (June 2009).

Coval, Joshua D., Jakub W. Jurek, and Erik Stafford. "The Economics of Structured Finance," Journal of Economic Perspectives 23, no. 1 (Winter 2009): 3-25.

Dang, Tri Vi, Gary Gorton, and Bengt Holmstrom. "Opacity and the Optimality of Debt for Liquidity Provision," working paper, 2010.

Davila, Eduardo. "Dissecting Fire Sales Externalities," Harvard University working paper, 2011.

DeMarzo, Peter. "The Pooling and Tranching of Securities: A Model of Informed Intermediation," Review of Financial Studies, 2005, 18, 1-35.

Diamond, Douglas and Raghuram Rajan. "Fear of Fire Sales, Illiquidity Seeking, and the Credit Freeze," Quarterly Journal of Economics 2011, 126, 557-591. 
Dudley, William. "A Preliminary Assessment of the TALF," Available at: http://www.newyorkfed.org/newsevents/speeches/2009/dud090604.html, June 2009.

Duffie, Darrell. "Asset Price Dynamics with Slow-Moving Capital," American Finance Association Presidential Address, Journal of Finance 2010, Volume 65: 1238-1268.

Duffie, Darrell and Peter DeMarzo. "A Liquidity Based Model of Security Design," Econometrica 67 (1999).

Duffie, Darrell, Nicolae Garleanu, and Lasse Pedersen. "Over-the-Counter Markets," Econometrica 2005, Volume 73: 1815-1847.

Duffie, Darrell, Nicolae Garleanu, and Lasse Pedersen. "Valuation in Over-the-Counter Markets," Review of Financial Studies 2007, Volume 20: 1865-1900.

Geanakoplos, John. "The Leverage Cycle," NBER Macroeconomics Annual 2009. Chicago: University of Chicago Press, vol. 24, pp. 1-65.

Gennaioli, Nicola, Andrei Shleifer, and Robert Vishny. "Financial Innovation and Financial Fragility," Journal of Financial Economics, 2011.

Gorton, Gary. "The Subprime Panic," NBER Working Paper 14398, 2008.

Gorton, Gary. "The Panic of 2007," NBER Working Paper 14358, 2008.

Gorton, Gary and Andrew Metrick. "Haircuts," Federal Reserve Bank of St. Louis Review, November/December, pp. 507-519, 2010.

Gorton, Gary and Andrew Metrick. "Securitized Banking and the Run on Repo," Journal of Financial Economics, 2011.

Gorton, Gary and George Pennacchi. "Financial Intermediaries and Liquidity Creation," The Journal of Finance, Vol. 45, No. 1. (Mar., 1990), pp. 49-71.

Grossman, Sanford and Joseph Stiglitz. "On the Impossibility of Informationally Efficient Markets," The American Economic Review, Vol. 70, No. 3 (Jun., 1980), pp. 393-408.

Hart, Oliver and J. Moore, "Incomplete Contracts and Renegotiation," Econometrica Vol. 56, No. 4 (Jul., 1988), pp. 755-785.

He, Zhiguo, In Gu Khang, and Arvind Krishnamurthy. "Balanced Sheet Adjustments in the 2008 Crisis," IMF Economic Review, 2010.

Kohn, Donald. "Policies to Bring Us Out of the Financial Crisis and Recession," April 2009.

Merton, Robert. "A Simple Model of Capital Market Equilibrium with Incomplete Information," The Journal of Finance, Vol. 42, No. 3, (July, 1987), pp. 483-510.

Modigliani, Franco and Merton Miller. "The Cost of Capital, Corporation Finance and the Theory of Investment," American Economic Review 48 (3): 261-297, 1958. 
Myers, Stewart and Nicholas Majluf. "Corporate financing and investment decisions when firms have information that investors do not have," Journal of Financial Economics, Vol. 13, No. 2, (June, 1984), pp. 187-221.

Pacelle, Mitchell and Gregory Zuckerman. "Debt Damage: Losses Spread On Specialized Bond Products," Wall Street Journal, July 31, 2001.

Pagano, Marco and Paolo Volpin. "Securitization, Transparency, and Liquidity," Review of Financial Studies, 2012, 25, 2417-2453.

Rubinstein, Ariel and Asher Wolinsky. "Equilibrium in a Market with Sequential Bargaining", Econometrica 53(5), pp. 1133-1150, 1985.

Shleifer, Andrei and Robert Vishny. "Unstable Banking," Journal of Financial Economics, 2010.

Shleifer, Andrei and Robert Vishny. "Asset Fire Sales and Credit Easing," American Economic Review Papers and Proceedings, May, 2010.

Stein, Jeremy. "Monetary Policy as Financial-Stability Regulation," Quarterly Journal of Economics, 2012 .

Stiglitz, Jospeh E. and Andrew Weiss, "Credit Rationing in Markets with Imperfect Information," American Economic Review Vol. 71, No. 3 (June, 1981), pp. 393-410. 


\section{A Microfounding the Market Power of the Informed}

In the main text, we assume that the return earned by informed investors is a function of their scarcity: $r_{S}=r\left[K, e_{S}\right]$ where $e_{S}=1-P\left[d_{S} ; D\right]$ is originators demand for equity. We assumed that $r[\cdot]$ has three properties:

1. Returns to informed capital exceed $c$ when it is maximally scarce: $r\left[K, e_{S}\right]>c$ when $K \leq e_{S}$.

2. Informed capital earns a higher return when it is more scarce: $\partial r / \partial K<0$ and $\partial(r[K, e] \cdot e) / \partial e>$ 0 .

3. There is a financing friction that prevents informed investors from capturing the full surplus associated with loan pools even when they are maximally scarce: $r_{L}<\left(V_{L}-1\right) / e_{L}$ where $V_{L}=\theta v^{G}+(1-\theta) v_{L}^{B}$ the expected value of the average loan pool in the low state.

\section{A.1 Walrasian Pricing}

If we assume Walrasian pricing, then we will have $r\left[K, e_{S}\right]=0$ when $K>e_{S}$ and $r\left[K, e_{S}\right]=$ $(1-w)\left(V_{S}-1\right) / e_{S}$ when $K \leq e_{S}$. Here $0<w<1$ is the financing wedge; informed investors can only capture fraction $(1-w)$ of the loan pool surplus even when they are maximally scarce. Now condition (6) in the main text reduces to

$$
(1-p) \cdot r\left[1-d_{L}^{*}, 1-d_{L}^{*}\right]=(1-p)(1-w)\left(V_{L}-1\right) /\left(1-v_{L}^{B}\right)<c .
$$

If this condition is met, then if $1-v_{L}^{B}$ investors (enough to fund all loan pools in the low state) become informed, they will not earn enough to recoup their infrastructure costs. In this case, then exactly $1-v_{H}^{B}$ investors become informed and there will be underfunding in the low state. The planner then can set $d_{H}^{* *}=v_{L}^{B}$ to ensure that all projects are funded in the low state. Social welfare is greater in the planner's solution than the private market outcome if

$p\left(V_{H}-1\right)+(1-p) \frac{1-v_{H}^{B}}{1-v_{L}^{B}}\left(V_{L}-1\right)-c\left(1-v_{H}^{B}\right)<p\left(V_{H}-1\right)+(1-p)\left(V_{L}-1\right)-c\left(1-v_{L}^{B}\right)$

which reduces to the familiar condition $(1-p)\left(V_{L}-1\right) /\left(1-v_{L}^{B}\right)>c$.

\section{A.2 Search Version}

To obtain returns that are continuous in the scarcity of informed investors, we use a variant of the search/bargaining model of Rubinstein and Wolinsky (1985). Let the discount rate be $\rho$. In our case, the mass of originators (i.e., potential sellers) is $e_{S}$ and the mass of informed investors (i.e., potential buyers) is $K$, so the fraction of buyers is $\mu=K /\left(K+e_{S}\right)$. Investors and originators bargain over the fraction of total surplus $\left(V_{S}-1\right)$ that each will receive, with the originator receiving fraction $\lambda$ and the investor receiving fraction $1-\lambda$. The rate at which investors meet originators is proportional to the number of originators, $\alpha(1-\mu)$, and the rate at which originators meet investors is proportional to the number of investors, $\alpha \mu$, for some exogenous contact rate $\alpha$. 
Let $W_{I}$ and $W_{O}$ be the value functions for investors and originators at the beginning of the game. Given a bargaining outcome $\Lambda$, these can be written as

$$
\begin{gathered}
\rho W_{I}=\alpha(1-\mu)\left((1-\Lambda)-W_{I}\right) \\
\rho W_{O}=\alpha \mu\left(\Lambda-W_{O}\right) .
\end{gathered}
$$

In the bargaining game, either the investor or originator is randomly chosen and offers a division, $\lambda$. If there is no agreement, the investor and originator wait for interval $\delta$ and then one is randomly selected and offers another division. However, in interval $\delta$ either party can meet a new bargaining partner and leave the current negotiation. One can show that as $\delta \rightarrow 0$, the subgame perfect equilibrium in the game is given by the Nash bargaining solution with $W_{I}$ and $W_{O}$ as the threat points. ${ }^{15}$ Thus, $\lambda$ maximizes $\left(\lambda-W_{O}\right)\left(1-\lambda-W_{I}\right)$, so we have

$$
\lambda=\frac{1}{2}\left(1+W_{O}-W_{I}\right)
$$

In equilibrium, we have $\Lambda=\lambda$ and solving (10), (11), and (12) for $\lambda$ yields

$$
\lambda=\frac{\rho+\alpha \mu}{\alpha+2 \rho} .
$$

Taking the limit as $\rho \rightarrow 0$ yields $\lambda=\mu$.

Thus, the informed investors (buyers) capture fraction $(1-\lambda)=(1-\mu)=e_{S} /\left(K+e_{S}\right)$ of the surplus. This fraction is decreasing in $K$ and increasing in $e_{S}$, the amount of equity financing backing each project. The informed investors (buyers) capture $(1-\lambda)$ of the surplus $\left(V_{S}-1\right)$ in return for an investment of $e_{S}$, so the return they earn per dollar invested is

$$
r_{S}=(1-\lambda) \frac{\left(V_{S}-1\right)}{e_{S}}=\frac{V_{S}-1}{K+e_{S}}
$$

Note that

$$
r_{S}=\frac{V_{S}-1}{K+e_{S}}<\frac{V_{S}-1}{e_{S}}
$$

so long as $K>0$. Furthermore, note that $\partial r_{S}\left[K, e_{S}\right] / \partial K<0$ and $\partial r_{S}\left[K, e_{S}\right] / \partial e_{S}<0$. The total dollar return earned by the informed per pool is

$$
r_{S}\left[K, e_{S}\right] \cdot e_{S}=(1-\lambda)\left(V_{S}-1\right)=\frac{e_{S}}{K+e_{S}}\left(V_{S}-1\right)
$$

which is increasing in $e_{S}$ and decreasing in $K$. Thus, $r_{S}\left[K,\left(1-P\left[D, d_{S}\right]\right)\right] \cdot\left(1-P\left[D, d_{S}\right]\right)$ is decreasing in $d_{S}{ }^{16}$ Thus, properties 2 and 3 of the return function assumed in the main text follow from this simple model of search/bargaining.

\footnotetext{
${ }^{15}$ As $\delta \rightarrow 0$, the prices proposed by the buyer and seller converge to the same limit.

${ }^{16}$ This model also implies that the return earned by uninformed investors is 0 since the mass of buyers (uninformed investors) is infinite and the mass of sellers is finite.
} 


\section{B Proofs}

\section{B.1 Proof of Proposition 1}

We first show that the originator's problem is equivalent to maximizing $P\left[d_{S} ; E\right]+P\left[d_{S} ; D\right]$. Let $V_{E}\left[d_{S}\right]=\left(1+r_{S}\right) \cdot P\left[d_{S} ; E\right]$ be the value the equity of the loan pool. To raise $1-P\left[d_{S} ; D\right]$ dollars from informed equity investors, the originator must sell fraction $\left(1-P\left[d_{S} ; D\right]\right)\left(1+r_{S}\right) / V_{E}\left[d_{S}\right]$ of the equity in the pool. Thus, the value of the stake retained by the originator is

$$
V_{E}\left[d_{S}\right]\left(1-\frac{\left(1-P\left[d_{S} ; D\right]\right)\left(1+r_{S}\right)}{V_{E}\left[d_{S}\right]}\right)=\left(1+r_{S}\right)\left(P\left[d_{S} ; E\right]+P\left[d_{S} ; D\right]-1\right) .
$$

Since originators take $r_{S}$ as fixed, this is equivalent to maximizing $P\left[d_{S} ; E\right]+P\left[d_{S} ; D\right]$.

We next show that (as assumed in the text) that only uninformed investors purchase debt in primary markets and that only informed investors purchase equity. First, uninformed investors would be willing to pay $\theta\left(1-M \ell(M+\ell)^{-1}\right)\left(v^{G}-v_{S}^{B}\right)$ for equity claims, while informed investors are willing to pay $\theta\left(v^{G}-v_{S}^{B}\right) /\left(1+r_{S}\right)$. Since $(3)$ implies $1-M \ell(M+\ell)^{-1}<$ $1 /\left(1+r_{S}\right)$, informed investors have higher valuations and, thus, only informed investors purchase equity.

We now provide conditions under which only uninformed investors purchase debt. Recall that the uninformed value risky debt according to

$$
P\left[D ; d_{S}\right]=\theta \min \left\{v^{G}, d_{S}\right\}+(1-\theta) \min \left\{v_{S}^{B}, d_{S}\right\}-\theta \ell \frac{M}{M+\ell}\left(\min \left\{v^{G}, d_{S}\right\}-\min \left\{v_{S}^{B}, d_{S}\right\}\right) .
$$

How do the informed value risky debt? Since they will opportunistically sell any bad pools when not hit by liquidity shocks we have

$$
\begin{aligned}
V_{I}\left[D ; d_{S}\right]= & \overbrace{\theta(1-\ell) \min \left\{v^{G}, d_{S}\right\}}^{\text {Good pool, no liquidity shock }}+\overbrace{\theta \ell P_{2}\left[d_{S} ; D\right]}^{\text {Good pool, forced sale }}+\overbrace{(1-\theta) P_{2}\left[d_{S} ; D\right]}^{\text {Bad pool }} \\
= & \theta \min \left\{v^{G}, d_{S}\right\}+(1-\theta) \min \left\{v_{S}^{B}, d_{S}\right\} \\
& -\theta \ell \frac{M-(1-\theta)(1-\ell)}{M+\ell}\left(\min \left\{v^{G}, d_{S}\right\}-\min \left\{v_{S}^{B}, d_{S}\right\}\right) .
\end{aligned}
$$

Due to their ability to opportunistically unload bad pools at $t=2$, the informed have a weakly higher valuation of debt and a strictly higher valuation of risky debt (i.e., when $\min \left\{v^{G}, d_{S}\right\}-$ $\left.\min \left\{v_{S}^{B}, d_{S}\right\}>0\right)$. Thus, by deviating from the proposed equilibrium and purchasing risky debt at the market price the informed can earn a certain return of

$$
\begin{aligned}
& \frac{V_{I}\left[D ; d_{S}\right]-P\left[D ; d_{S}\right]}{P\left[D ; d_{S}\right]} \\
= & \theta \ell \frac{(1-\theta)(1-\ell)}{M+\ell} \frac{\min \left\{v^{G}, d_{S}\right\}-\min \left\{v_{S}^{B}, d_{S}\right\}}{P\left[D ; d_{S}\right]} \\
= & \theta \ell(1-\theta)(1-\ell) \frac{\min \left\{v^{G}, d_{S}\right\}-\min \left\{v_{S}^{B}, d_{S}\right\}}{(M(1-\ell)+\ell) \theta\left(\min \left\{v^{G}, d_{S}\right\}-\min \left\{v_{S}^{B}, d_{S}\right\}\right)+(M+\ell) \min \left\{v_{S}^{B}, d_{S}\right\}}
\end{aligned}
$$

By contrast if they participate in the primary equity market they will earn a return of $r_{S}$ with 
probability $\left(1-P\left[D ; d_{S}\right]\right) / K$. As a result, the informed will use all of their capital to purchase equity if

$$
\theta \ell \frac{(1-\theta)(1-\ell)}{M+\ell} \frac{\min \left\{v^{G}, d_{S}\right\}-\min \left\{v_{S}^{B}, d_{S}\right\}}{P\left[D ; d_{S}\right]}<r_{S} \cdot \frac{\left(1-P\left[D ; d_{S}\right]\right)}{K} .
$$

Obviously, this condition holds at the private market equilibrium where $d_{S}=v_{S}^{B}$ and $r_{S}>0$. Otherwise, the condition is non-trivial and primary market separation need not always obtain when debt is risky. However, the condition will always hold for $M$ sufficiently large and we assume that this is the case. Specifically, as $M \rightarrow \infty$, secondary prices converge to $\min \left\{v_{S}^{B}, d_{S}\right\}$ which eliminates that ability of the informed to profit from opportunistic secondary sales, so both $P\left[D ; d_{S}\right]$ and $V_{I}\left[D ; d_{S}\right]$ converge to $\theta \min \left\{v^{G}, d_{S}\right\}+(1-\theta) \min \left\{v_{S}^{B}, d_{S}\right\}-$ $\theta \ell\left(\min \left\{v^{G}, d_{S}\right\}-\min \left\{v_{S}^{B}, d_{S}\right\}\right)$. As a result, the left-hand-side of (14) converges to 0 while the right-hand-side of (14) remains positive. Thus, the analysis in the main text implicitly assumes that $M$ is large enough so that (14) holds.

Finally, the fact that $K^{*}<1-d_{L}^{*}$ follows from condition (6), the zero-profit condition of the informed (4), and the continuity of the scarcity returns earned by the informed $r[\cdot]$.

\section{B.2 Proof of Proposition 2}

We first show that total originator surplus can be written as

$$
p N_{H}\left(V_{H}-1\right)+(1-p) N_{L}\left(V_{L}-1\right)-c K .
$$

The profits of originators are given by

$$
\begin{aligned}
& p N_{H}\left(1+r_{H}\right)\left(P\left[d_{H} ; E\right]+P\left[d_{H} ; D\right]-1\right) \\
& +(1-p) N_{L}\left(1+r_{L}\right)\left(P\left[d_{L} ; E\right]+P\left[d_{L} ; D\right]-1\right) .
\end{aligned}
$$

The profits of uninformed investors are given by

$$
\begin{aligned}
& p N_{H}\left((1-\ell) E\left[\min \left\{v_{H}, d_{H}\right\}\right]+\ell P_{2}\left[d_{H} ; D\right]-P\left[d_{H} ; D\right]\right) \\
& +(1-p) N_{L}\left((1-\ell) E\left[\min \left\{v_{L}, d_{L}\right\}\right]+\ell P_{2}\left[d_{L} ; D\right]-P\left[d_{L} ; D\right]\right) .
\end{aligned}
$$

The profits of informed investors are given by

$$
\begin{aligned}
& p\left(N_{H} r_{H}\left(1-P\left[d_{H} ; D\right]\right)+\frac{M}{M+\ell} \ell \theta\left(\min \left\{v^{G}, d_{H}\right\}-\min \left\{v_{S}^{B}, d_{H}\right\}\right)\right) \\
& +(1-p)\left(N_{L} r_{L}\left(1-P\left[d_{L} ; D\right]\right) \frac{M}{M+\ell} \ell \theta\left(\min \left\{v^{G}, d_{L}\right\}-\min \left\{v_{S}^{B}, d_{L}\right\}\right)\right)-c K
\end{aligned}
$$

Summing yields $p N_{H}\left(V_{H}-1\right)+(1-p) N_{L}\left(V_{L}-1\right)-c K$ as desired. Since investor and market maker profits are zero it follows that total social surplus equals to originator surplus.

As discussed in the text, we will always have $N_{H}=1$ since $r>c$ when informed investors are maximally scarce. Enough investors become informed to fund all loan pools in the high state. Now define $K\left[d_{H}\right]$ implicitly using the zero profit condition (4) and use the relation 
$N_{L}=K\left[d_{H}\right] /\left(1-v_{L}^{B}\right)$ to write total surplus as

$$
p\left(V_{H}-1\right)+(1-p) \frac{K\left[d_{H}\right]}{1-v_{L}^{B}}\left(V_{L}-1\right)-c K\left[d_{H}\right] .
$$

Differentiating with respect to $d_{H}$ yields

$$
\left((1-p) \frac{V_{L}-1}{1-v_{L}^{B}}-c\right) \frac{\partial K}{\partial d_{H}}
$$

Write the zero profit condition of the informed as $0=\Pi\left(K, d_{H}, d_{L}^{*}[K]\right)$. Then we have $\operatorname{sign}\left(\partial K^{*} / \partial d_{S}\right)=\operatorname{sign}\left(-\left(\partial \Pi / \partial d_{H}\right) /(\partial \Pi / \partial K)\right)=\operatorname{sign}\left(\partial \Pi_{H} / \partial d_{H}\right)$. So to sign $\partial K / \partial d_{H}$, we only need to sign $\partial \Pi_{H} / \partial d_{H}$. Assuming $N_{H}=1$, we have

$$
\frac{\partial \Pi_{H}}{\partial d_{H}}=\overbrace{\frac{\partial}{\partial d_{H}}\left[r_{H}\left[K,\left(1-P\left[d_{H} ; D\right]\right)\right]\left(1-P\left[d_{H} ; D\right]\right)\right]}^{<0}+\overbrace{\frac{M}{M+\ell} \ell \theta\left(1\left[d_{H}>v_{H}^{B}\right]-1\left[d_{H}>v^{G}\right]\right)}^{\geq 0} .
$$

For $d_{H}<v_{H}^{B}$, the second term is zero so we have $\partial \Pi_{H} / \partial d_{H}<0$. Thus, for $d_{H}<v_{H}^{B}$ we will have $\partial K / \partial d_{H}<0$, so the planner will be able to increase total surplus by decreasing $d_{H}$ so long as condition (8) holds.

Note that the planner can achieve full funding in the low state using such interventions. Specifically, if the planner were to set $d_{H}^{* *}=d_{L}^{*}=v_{L}^{B}$, at least $1-v_{L}^{B}$ investors would become informed because they would be maximally scarce in both states and earn returns greater than $c$. The planner can do better and will set $d_{H}^{* *}$ such that $d_{L}^{*}<d_{H}^{* *}<d_{H}^{*}$ and $K^{* *}=K\left[d_{H}^{* *}\right]=1-v_{L}^{B}$ so all loan pools are funded in the low state. We also need to check that uninformed investors have a lower valuation for equity than informed investors at $d_{H}^{* *}$. This generally will be the case because condition (3) holds at the private market solution. The entry of informed capital offsets the increased demand for informed capital when we move from the private market solution to the planner's solution so $r\left[K^{* *}, 1-d_{H}^{* *}\right]$ will be similar to $r\left[K^{*}, 1-d_{H}^{*}\right]$.

\section{B.3 Proof of Proposition 3}

When $v_{H}^{B}<d_{H}<v^{G}$ we have

$$
\frac{\partial \Pi_{H}}{\partial d_{H}}=\left(1-P\left[d_{H} ; D\right]\right) \frac{\partial r_{H}}{\partial d_{H}}-\theta r_{H}\left(1-\frac{M}{M+\ell} \ell\right)+\frac{M}{M+\ell} \ell \theta .
$$

The sum of the last two terms is greater than zero when condition (3) holds, i.e. exactly when the originators want to issue risk-free debt. Thus, if we also have $\partial r_{H} / \partial e_{H}<0$ so that $\partial r_{H} / \partial d_{H}>0$, as is the case in the search model outlined in Appendix A, (3) ensures that we always have $\partial \Pi_{H} / \partial d_{H}>0$ for $v_{H}^{B}<d_{H}<v^{G}$. However, if $\partial r_{H} / \partial d_{H}<0$, as in the numerical example in Section 2.3, then the sign of $\partial \Pi_{H} / \partial d_{H}>0$ would depend on the magnitude of $\partial r_{H} / \partial d_{H}$. Specifically, if $\partial r_{H} / \partial d_{H}<0$, then (3) is only a necessary condition to have $\partial \Pi_{H} / \partial d_{H}>0$. 
More generally, we have $\partial \Pi_{H} / \partial d_{H}>0$ when

$$
\frac{\partial r_{H}}{\partial d_{H}}>-\left(1-P\left[d_{H} ; D\right]\right)^{-1} \frac{\theta}{1+r_{H}}\left[\frac{M}{M+\ell} \ell-\left(1-\frac{1}{1+r_{H}}\right)\right] .
$$

When (3) holds, the right hand side of this inequality is negative. So raising the face value of debt increases the number of informed investors so long as $\partial r_{H} / \partial d_{H}$ is not too negative.

When the planner can encourage investors to become informed by raising $d_{H}$ to make the debt riskier, the fact that originators only need to raise $\$ 1$ is a constraint on such interventions. Specifically, the planner cannot force originators to raise more than $\$ 1$ of total financing. Thus, the planner can only raise $d_{H}$ to the point where the price of debt equals 1 . When raising $d_{H}$ the planner is subject to the constraint that $P\left[d_{H} ; D\right] \leq 1$. Thus, for $v_{H}^{B}<d_{H}<v^{G}$, the maximum value of $d_{H}$ satisfies

$$
1=\theta d_{H}+(1-\theta) v_{H}^{B}-\theta \ell M(M+\ell)^{-1}\left(d_{H}-v_{H}^{B}\right) \Rightarrow d_{H}=v_{H}^{B}+\frac{1-v_{H}^{B}}{\theta\left(1-\ell M(M+\ell)^{-1}\right)} .
$$

This value of $d_{H}$ yields $[\ell M /(M(1-\ell)+\ell)]\left(1-v_{H}^{B}\right)$ of adverse selection profits for the informed in the good state.

To achieve full funding of loan pools in the low state, the planner must induce $K=1-v_{L}^{B}$ informed investors to enter. The zero profit condition for the informed would then be

$p\left(r_{H}\left(1-P\left[d_{H} ; D\right]\right)+\frac{M}{M+\ell} \ell \theta\left(\min \left\{v^{G}, d_{H}\right\}-\min \left\{v_{S}^{B}, d_{H}\right\}\right)\right)+(1-p) r_{L}\left(1-v_{L}^{B}\right)=c\left(1-v_{L}^{B}\right)$.

If

$$
\underbrace{\frac{\ell M}{M(1-\ell)+\ell}\left(1-v_{H}^{B}\right)}_{\text {maximum adverse selection profits }}>c\left(1-v_{L}^{B}\right)
$$

then the fact that $r>c$ when informed capital is maximally scarce implies that $(1-p) r_{L}\left(1-v_{L}^{B}\right)>$ $(1-p) c\left(1-v_{L}^{B}\right)$, so there is a feasible value of $d_{H}$ that satisfies this zero profit condition.

The left hand side of this expression gives the maximum adverse selection profits for the informed in the high state for the value of $d_{H}$ such that $P\left[d_{H} ; D\right]=1$. The right hand side is the information infrastructure cost needed to fully fund all loan pools in the low state. However, as discussed above, $1-v_{H}^{B}$ is likely to be small since the scope for adverse selection is low in good times. So this condition may be difficult to satisfy. Intuitively, the planner is trying to subsidize information production by creating more adverse selection, but it may be difficult to create enough adverse selection in good times to achieve the optimal subsidy level.

\section{B.4 Proof of Proposition 4}

We have

$$
d_{L}^{* * *}=v_{L}^{B}+\frac{c}{\gamma(1-p)(1-\theta)^{2}}
$$

Note that $d_{H}^{* * *}$ is a function of $d_{L}^{* * *}$ and $K^{* * *}$ is a function of $d_{H}^{* * *}$. Since $d_{L}^{* * *} \rightarrow d_{L}^{* *}$ as $\rightarrow \infty$, we will have $d_{H}^{* * *} \rightarrow d_{H}^{* *}$ and $K^{* * *} \rightarrow K^{* *}$ as well. The existence of $\bar{\gamma}$ is a consequence of the continuity of the triple $\left(K^{* * *}, d_{H}^{* * *}, d_{L}^{* * *}\right)$ in $\gamma$ and the fact that $d_{H}^{* *}<d_{H}^{*}$ and $K^{* *}>K^{*}$. 